\title{
Inhibition of receptor-localized PI3K preserves cardiac $\beta$-adrenergic receptor function and ameliorates pressure overload heart failure
}

\author{
Jeffrey J. Nienaber, ${ }^{1}$ Hideo Tachibana, ${ }^{1}$ Sathyamangla V. Naga Prasad,${ }^{1}$ \\ Giovanni Esposito, ${ }^{2}$ Dianqing Wu, ${ }^{3}$ Lan Mao, ${ }^{1}$ and Howard A. Rockman ${ }^{1}$ \\ ${ }^{1}$ Departments of Medicine, Cell Biology, and Genetics, Duke University Medical Center, Durham, North Carolina, USA \\ ${ }^{2}$ Division of Cardiology, Federico II University, Naples, Italy \\ ${ }^{3}$ University of Connecticut Health Center, Farmington, Connecticut, USA
}

\begin{abstract}
$\beta$-Adrenergic receptor ( $\beta \mathrm{AR}$ ) downregulation and desensitization are hallmarks of the failing heart. However, whether abnormalities in $\beta$ AR function are mechanistically linked to the cause of heart failure is not known. We hypothesized that downregulation of cardiac $\beta A R$ s can be prevented through inhibition of PI3K activity within the receptor complex, because PI3K is necessary for $\beta A R$ internalization. Here we show that in genetically modified mice, disrupting the recruitment of PI3K to agonist-activated $\beta A R s$ in vivo prevents receptor downregulation in response to chronic catecholamine administration and ameliorates the development of heart failure with pressure overload. Disruption of PI3K/ $\beta A R$ colocalization is required to preserve $\beta A R$ signaling, since deletion of a single PI3K isoform (PI3K $\gamma$ knockout) is insufficient to prevent the recruitment of other PI3K isoforms and subsequent $\beta A R$ downregulation with catecholamine stress. These data demonstrate a specific role for receptor-localized PI3K in the regulation of $\beta A R$ turnover and show that abnormalities in $\beta A R$ function are associated with the development of heart failure. Thus, a strategy that blocks the membrane translocation of PI3K and leads to the inhibition of $\beta$ AR-localized PI3K activity represents a novel therapeutic approach to restore normal $\beta \mathrm{AR}$ signaling and preserve cardiac function in the pressure overloaded failing heart.
\end{abstract}

J. Clin. Invest. 112:1067-1079 (2003). doi:10.1172/JCI200318213.

\section{Introduction}

Heart failure is a syndrome characterized by depressed ventricular function, fluid retention, and increased mortality (1). Classic characteristics of the failing heart include a reduction in $\beta$-adrenergic receptor ( $\beta \mathrm{AR}$ ) number and diminished contractile response to catecholamine stimulation, due in part to activation of the sympathetic nervous system $(2,3)$. Treatment of heart

Received for publication February 26, 2003, and accepted in revised form July 29, 2003.

Address correspondence to: Howard A. Rockman,

Duke University Medical Center, Duke University Medical Center Box 3104, Durham, North Carolina 27710, USA.

Phone: (919) 668-2521; Fax: (919) 668-2524;

E-mail: h.rockman@duke.edu.

Jeffrey J. Nienaber and Hideo Tachibana contributed equally to this work.

Conflict of interest: The authors have declared that no conflict of interest exists.

Nonstandard abbreviations used: $\beta$-adrenergic receptor ( $\beta A R$ ); G protein-coupled receptors (GPCRs); phosphatidylinositol (PtdIns); phosphoinositide kinase domain (PIK); phosphatidylinositol-3,4,5-tri-phosphate (PtdIns-3,4,5- $\mathrm{P}_{3}$ ); inactive mutant of PI3K $\gamma$ (PI3K $\gamma_{\text {inact }}$ ); PI3K $\gamma$ knockout (PI3K $\left.\gamma-\mathrm{KO}\right)$; hemagglutinin (HA); transverse aortic constriction (TAC); left ventricle (LV); PtdIns-3,4,5-tri-phosphate (PIP3); phosphoprotein kinase $\mathrm{B}(\mathrm{pPKB})$; phospho-glycogen synthase kinase (pGSK); extracellular signal-regulated kinase (ERK); LV weight/body weight (LVW/BW); isoproterenol (ISO);

immunoblotting (IB); c-terminal region of $\beta$-adrenergic receptor kinase-1 ( $\beta$ ARK1-ct). failure patients with beta-blockers may reverse this process, and recent clinical and experimental data support the concept that normalizing $\beta$ AR function can lead to improved cardiac function and prolonged survival (4-6). Despite these newer therapies, however, the mortality rate for patients with chronic heart failure remains high, indicating a need for novel strategies that are synergistic with current treatments.

$\beta$ ARs belong to the large family of $G$ protein-coupled receptors (GPCRs) that relay their signals by coupling to $G$ proteins and activating or inhibiting different effector molecules, such as an enzyme or ion channel (3, 7). Under conditions of heart failure there is a downregulation in the number of $\beta A R s$ and diminished contractile response to catecholamine stimulation, due in part to activation of the sympathetic nervous system (2, $3)$. Upon catecholamine binding to $\beta A R s$, the heterotrimeric $G$ proteins dissociate into $G_{\alpha}$ and $G_{\beta \gamma}$ subunits. The $G_{\alpha}$ subunit is free to activate the effector adenylyl cyclase to generate the second messenger cAMP and lead to an increase in heart rate and contractility. The termination of GPCR signals is initiated by phosphorylation of the agonist-occupied receptor primarily by the $G$ protein-coupled receptor kinase (commonly known as $\beta A R K 1$ ), followed by the binding of arrestin proteins. Receptor phosphorylation and arrestin binding not only act to sterically inhibit further $G$ protein activation, but is also the first step in the process of 
receptor internalization and downregulation (7), a process that we have shown to require the presence of PI3K within the agonist-occupied receptor complex (8).

PI3Ks are a conserved family of enzymes that catalyze the generation of D-3 phosphatidylinositols (PtdIns), which in turn regulate diverse cellular processes such as cell survival and proliferation, cytoskeletal arrangements, receptor endocytosis, and cardiac contractility (9-11). Based on their structure and substrate specificity, PI3Ks can be divided into three classes (I, II, and III). The class I PI3Ks can be further subdivided into class $\mathrm{I}_{\mathrm{A}}$ (activated by receptor tyrosine kinases, PI3K $\alpha$ ) and $I_{B}$ (activated by $G_{\beta \gamma}$ subunits of heterotrimeric $G$ proteins, PI3K $\gamma$ ). Recent studies have demonstrated important roles for both PI3K $\alpha$ and PI3K $\gamma$ in cardiac growth and function $(9,12,13)$. For instance, PI $3 \mathrm{~K} \gamma$ is upregulated in response to in vivo pressure-overload hypertrophy in the heart (14), and the absence or inhibition of PI3K $\gamma$ leads to enhanced cardiac contractility $(9,12)$. Moreover, overexpression of PI3K $\alpha$ mutants in hearts of transgenic mice leads to changes in the size of cardiomyocytes, indicating this isoform may be important for cell growth in the heart (13). Whether PI3K plays a role in the development of heart failure through its interaction with $\beta$ ARs is unknown.

PI3K binds to $\beta A R K 1$ through a helical domain known as the phosphoinositide kinase domain (PIK), which is conserved among all PI3K isoforms. Upon agonist stimulation, $\beta$ ARK1 mediates the translocation of PI3K to $\beta A R s$, allowing for the generation of phosphatidylinositol-3,4,5-tri-phosphate (PtdIns-3,4,5- $\left.\mathrm{P}_{3}\right)(8$, 10). The local generation of PtdIns- $3,4,5-\mathrm{P}_{3}$ within the receptor complex functions to enhance the recruitment of a number of phosphoinositide-binding endocytic proteins such as $\beta$-arrestin and AP-2, essential for $\beta$ AR internalization $(8,15)$. Furthermore, in cell culture systems, overexpression of a catalytically inactive PI3K or PIK domain that disrupts the interaction between PI3K and $\beta A R K 1$ by displacing both class $\mathrm{I}_{\mathrm{A}}$ and $\mathrm{I}_{\mathrm{B}}$ isoforms blocks agonist-stimulated $\beta A R$ internalization $(8,10)$.

Since $\beta A R K 1-$ mediated localization of PI3K is required for internalization of $\beta A R s$, we postulated that under conditions of excess catecholamines, similar to that found in chronic human heart failure, PI3K would play an important role in the chronic downregulation of $\beta A R s$. To test the hypothesis that $\beta A R$ downregulation and cardiac dysfunction could be prevented in vivo by blocking the $\beta$ ARK1-mediated recruitment of active PI3K, we studied mice with cardiac-specific overexpression of a catalytically inactive mutant of $\mathrm{PI} 3 \mathrm{~K} \gamma\left(\mathrm{PI} 3 \mathrm{~K} \gamma_{\text {inact }}\right)$ and PI3K $\gamma$ knockout mice $(\mathrm{PI} 3 \mathrm{~K} \gamma-\mathrm{KO})$ following exposure to chronic catecholamine administration or pressure overload-induced heart failure.

\section{Methods}

Generation of transgenic mice. The pCMV-PI3Kp110 $\gamma$ hemagglutinin (pCMV-PI3Kp110 $\gamma$-HA) mutant $\left(\mathrm{PI} 3 \mathrm{~K} \gamma_{\text {inact }}\right)(\Delta 942-981$, a deletion in the ATP-binding site) was a generous gift from Charles S. Abrams
(Department of Medicine, University of Pennsylvania Medical School, Philadelphia, Pennsylvania, USA) (16). The cDNA insert of PI3K $\gamma_{\text {inact }}$ was amplified using a $P f u$ platinum turbo Taq high-fidelity enzyme (Stratagene, La Jolla, California, USA) with a $5^{\prime}$ primer ( $5^{\prime}$ - TGCGGATCCGCCACCATGGAGCTGGAGAACTATAAACAG-3') containing ClaI for subcloning, followed by Kozak consensus sequence and $3^{\prime}$-primer $\left(5^{\prime}\right.$ ACCCGGGATCCTTAAGCGTAGTCTGGTACGT-3') with a ClaI site for subcloning. The PCR product was subcloned directly into a vector downstream of the $\alpha \mathrm{MyHC}$ gene promoter and upstream of an HA epitope and an SV40 polyadenylation site. The subcloned cDNA was sequenced and digested with restriction enzymes XhoI and NotI to check for orientation. Transgenic founders were identified by Southern blot analysis of tail DNA using the SV40 poly(A) as a probe. Transgenic founder mice were backcrossed into both DBA and C57BL/ 6 backgrounds for nine generations. The DBA background PI3K $\gamma_{\text {inact }}$ transgenic mice was used for the osmotic pump study while C57BL/ 6 was used in the transverse aortic constriction (TAC) studies. The PI3K $\gamma$ knockout mice were a generous gift from Dianquing $\mathrm{Wu}$ (University of Connecticut Health Center), and their method of generation has been published previously (17). The background of the PI3K $\gamma$ knockout mice was 129/B6, and 129/B6 mice were used as controls. Animals were handled according to the approved protocols and animal welfare regulations of the Institutional Review Board at Duke University Medical Center.

Echocardiography. Echocardiography was performed on conscious mice at 3-4 months of age with an HDI 5000 echocardiograph (ATL, Bothell, Washington, USA) as described previously (18).

Mini-osmotic pump implantation. Mini-osmotic pumps were implanted as described previously (19). Isoproterenol was dissolved in $0.002 \%$ ascorbic acid, and pumps (Alzet model 1007D; DURECT Corp., Cupertino, California, USA) were filled to deliver at a rate of $3 \mathrm{mg} / \mathrm{kg} / \mathrm{d}$ over a period of 7 days. In control mice pumps that delivered vehicle $(0.002 \%$ ascorbic acid) were implanted.

In vivo pressure overload. Mice were anesthetized with a mixture of ketamine $(100 \mathrm{mg} / \mathrm{kg})$ and xylazine $(2.5$ $\mathrm{mg} / \mathrm{kg}$ ), and TAC was performed as described previously (18). Twelve weeks after surgery, the transstenotic pressure gradient was assessed by recording simultaneous measurement of right carotid and left axillary arterial pressures.

Hemodynamic evaluation in mice. Hemodynamic evaluation was performed as described previously (20). Hemodynamic measurements were recorded at baseline and 45 seconds after infusion of incremental doses of isoproterenol (50,500, and 1,000 pg). Hemodynamic measurements were analyzed by SONOVIEW software (Sonometrics Corp., London, Ontario, Canada).

Membrane fractionation, lipid kinase assay, $\beta A R$ radioligand binding and adenylyl cyclase activity. Total PI3K and PI3K $\gamma$ assays from the left ventricles (LV) flash-frozen 


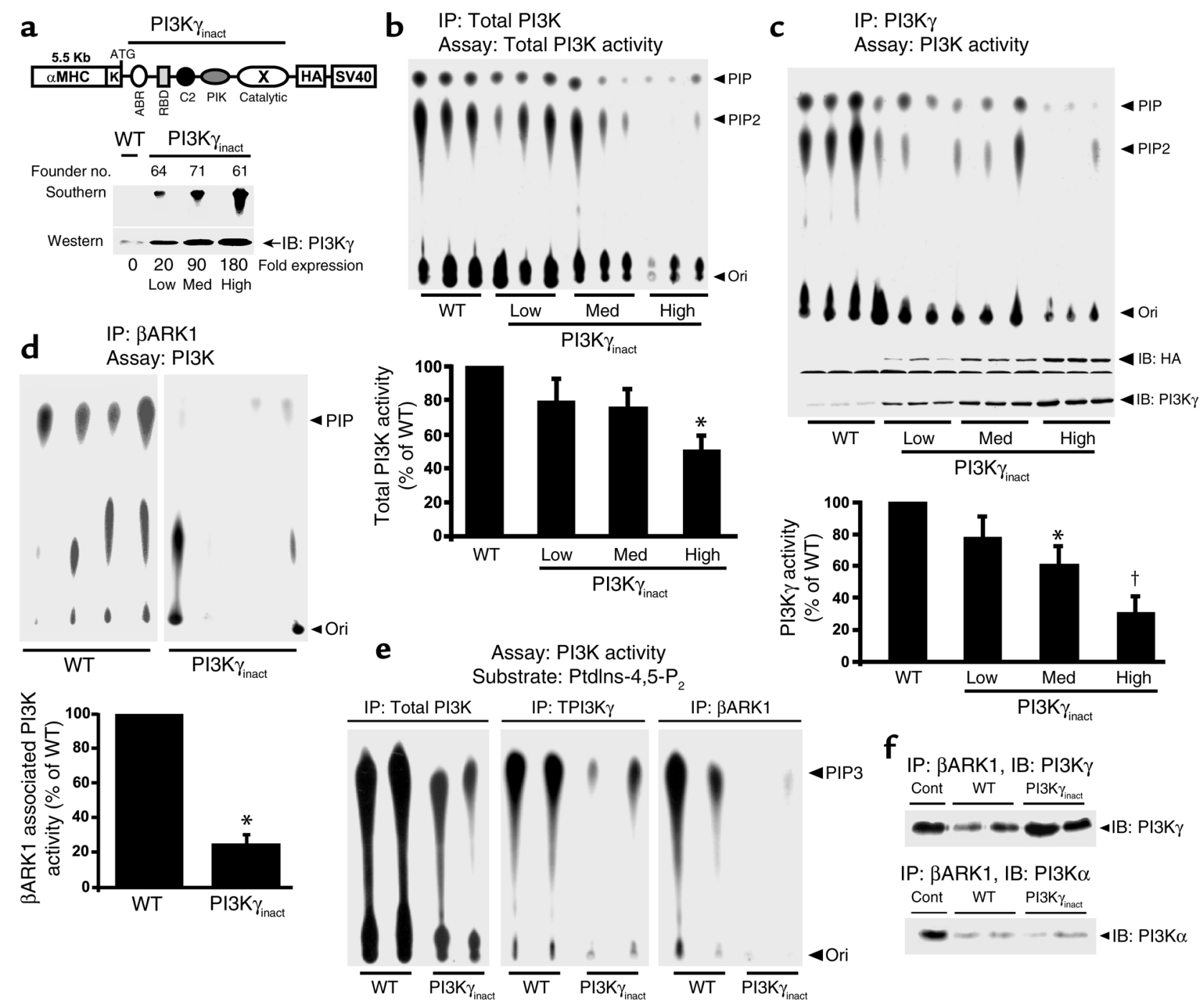

Figure 1

Generation of transgenic mice with decreased cardiac $\beta A R$-localized PI3K activity. (a) Diagram of the transgene construct containing the $\mathrm{PI} 3 \mathrm{~K} \gamma_{\text {inact }} \mathrm{cDNA}$ (upper panel). Southern $(10 \mu \mathrm{g}$ of DNA) and Western blots (100 $\mu \mathrm{g}$ of cytosolic extract) from WT and three transgenic founder lines using SV-40 probe and anti-PI3K $\gamma \mathrm{Ab}$, respectively (lower panel). (b and c) Basal levels of total PI3K (b) and PI3K $\gamma(\mathbf{c})$ activity in the LV relative to WT ( $n=9$, WT and transgenic lines); $2 \mathrm{mg}$ of cytosolic extract was used for immunoprecipitation with PI3K Ab. ${ }^{*} P<0.05$ versus WT; ${ }^{\dagger} P<0.01$ versus WT. (d) Basal $\beta$ ARK 1 -associated PI3K activity in the LV of WT $(n=6)$ and 180 -fold overexpressing transgenic mice $(n=6) ; 4 \mathrm{mg}$ of cytosolic extract was used for immunoprecipitation with $\beta$ ARK1 mAb. (e) Total PI3K, PI3K $\gamma$, and $\beta A R K 1$ associated PI3K activity in the left LVs measured by their ability to phosphorylate Ptdlns-4,5-P to Ptdlns-3,4,5- $\mathrm{P}_{3}$. (f) Immunoblotting for $\mathrm{PI} 3 \mathrm{~K} \alpha$ or PI3K $\gamma$ following immunoprecipitation with $\beta$ ARK $1 \mathrm{mAb}$ from clarified myocardial lysates $(3 \mathrm{mg})$. ${ }^{*} P<0.001$ versus WT. IP, immunoprecipitation; $\alpha \mathrm{MHC}$, alpha myosin heavy chain promoter; K, Kozak sequence; $C 2$, similar to type II C2 domain found in phospholipase $\mathrm{C} \delta 1$; X, catalytically inactive; $\mathrm{ABR}$, adaptor binding region; RBD, ras-binding domain; HA, hemagglutinin epitope tag; PIP, phosphatidylinositol mono-phosphate; PIP2, phosphatidylinositol bis-phosphate; Ori, origin; Cont (plus control), immunoprecipitation of $\mathrm{PI} 3 \mathrm{~K} \alpha$ or $\mathrm{PI} 3 \mathrm{~K} \gamma$ with its respective $\mathrm{Ab}$ and immunoblotted for $\mathrm{PI} 3 \mathrm{~K} \alpha$ or $\mathrm{PI} 3 \mathrm{~K} \gamma ; \beta \mathrm{ARK}, \beta$-adrenergic receptor kinase.

in liquid $\mathrm{N}_{2}$ were carried out as described previously (10). Membrane fractions were prepared as described previously (18). For the $\beta A R K 1$-associated PI3K assay, $500 \mu \mathrm{g}$ of membrane fraction was used for immunoprecipitation with the $\mathrm{C} 5 / 1 \mathrm{mAb}$ directed against BARK1 (10). To directly measure the generation of PtdIns-3,4,5-tri-phosphate (PIP3), in vitro lipid kinase assays were performed using the substrate PtdIns-4,5$\mathrm{P}_{2}$, which can be used by class I PI3Ks to generate PtdIns-3,4,5- $\mathrm{P}_{3}$. The lipids were extracted with chlo- roform/methanol (ratio of 1:1), and organic phase was spotted on TLC plates and resolved chromatographically with $2 \mathrm{~N}$ glacial acetic acid/1-propanol (ratio of 35:65). Dried plates were exposed, and autoradiographic signals were quantitated using BioRad Phosphorimager. Receptor binding with $25 \mu \mathrm{g}$ of the membrane fraction was performed as described previously (18) using $\beta A R$ ligand ([125I] cyanopindolol, $250 \mathrm{pM}$ ). All assays were performed in triplicate, and receptor density (in femtomoles) was nor- 
malized to milligrams of membrane protein. Adenylyl cyclase assays were performed as described previously (18) using $20 \mu \mathrm{g}$ of the membrane fraction. Generated cAMP was quantified using a liquid scintillation counter (MINAXI $\beta$-4000).

BARK1 activity by rhodopsin phosphorylation. Membrane $(50 \mu \mathrm{g})$ and cytosolic fraction $(150 \mu \mathrm{g})$ were incubated with rhodopsin-enriched rod outer segments with $10 \mathrm{mM} \mathrm{MgCl}_{2}$ and $100 \mu \mathrm{M}$ ATP containing $\left[\gamma^{-32} \mathrm{P}\right]$ ATP. The reactions were incubated in white light for 15 minutes, stopped, resolved by SDSPAGE gel, and autoradiography was carried out as described previously (18).

Immunoblotting. Immunoblotting was done as described previously (18). Immunoprecipitating Ab's were added to $500 \mu \mathrm{g}$ of membrane fraction. Ab's to phospho-protein kinase B (pPKB) and phosphoglycogen synthase kinase (pGSK) were used for blotting at 1:1,000, anti-hemagglutinin (PI3K $\left.\gamma_{\text {inact }}-\mathrm{HA}\right)$ at $1: 500$, and 1:10,000 for $\beta$ ARK1. Detection was carried out using ECL (Amersham Biosciences Corp., Piscataway, New Jersey, USA), and bands were quantified with densitometry.

$M A P K$. MAPK activities were assessed from clarified LV extracts as the capacity of immunoprecipitated extracellular signal-regulated kinase-p42/extracellular signal-regulated kinase-44 (ERK-p42/ERK-p44), p38, p38 $\beta$, and JNK-p46/JNK3 MAPK to phosphorylate in vitro substrates (myelin basic protein or GST-JUN) as described previously (18).

Survival studies. Survival data were analyzed by using a Kaplan-Meier survival analysis with a log-rank method of statistics. Survival analysis excluded mice that died within 3 days after surgery (TAC) and mice that had a pressure gradient of less that $15 \mathrm{mmHg}$ for both WT and PI3K $\gamma_{\text {inact }}$ mice.

Statistical analysis. Data are expressed as mean plus or minus SEM. Two-way repeated-measures ANOVA was used to evaluate hemodynamic measurement under basal and isoproterenol treatment and for analysis of cardiac function after TAC. Posthoc analysis was performed with a Scheffé test. Two-sample comparisons were performed with Student's $t$ tests. The Student's $t$ test with Bonferroni correction for multiple comparisons was used to evaluate data from the isoproterenol time course. For all analysis, a value of $P$ less than 0.05 was considered significant.

\section{Results}

Mice overexpressing PI $3 K \gamma_{\text {inact }}$ have decreased basal PI $3 K$ and $\beta A R K 1$-associated PI3K activity. We generated PI3K $\gamma_{\text {inact }}$ mice by subcloning $\mathrm{PI} 3 \mathrm{~K} \gamma_{\text {inact }}$ downstream of the aMHC promoter (Figure 1a, upper panel), which is expressed in cardiomyocytes (21). Three founders (numbers 64, 71, and 61) were generated, characterized by 20-, 90- and 180-fold overexpression of the mutant protein relative to WT (Figure 1a, lower panel). Robust total PI3K activity in WT mice was observed without a significant reduction in activity among the 20- and 90fold overexpressing PI3K $\gamma_{\text {inact }}$ transgenic mice. The 180fold overexpressing PI3K $\gamma_{\text {inact }}$ mice showed a $45 \%$ reduction in total PI3K compared with the WT (Figure $1 b)$. Assays specific for the PI3K $\gamma$ isoform showed $40 \%$ and $65 \%$ reductions in PI3K $\gamma$ activity in the hearts from the 90 - and 180-fold overexpressing transgenic mice, respectively (Figure 1c).

Since we have previously shown a direct interaction between $\beta$ ARK1 and PI3K $(8,10)$, we used the 180 -fold overexpressing mice to determine whether the PI3K $\gamma_{\text {inact }}$ transgenic mice had decreased $\beta$ ARK1-associated PI3K activity by immunoprecipitating $\beta$ ARK1 from left ventricular lysates and assaying for PI3K activity. Importantly, there was a marked reduction in $\beta$ ARK1-associated PI3K activity in PI3K $\gamma_{\text {inact }}$ hearts compared with WT (Figure 1d). We next tested the ability of WT and PI3K $\gamma_{\text {inact }}$ transgenic mice (180-fold) to generate PIP3,

\section{Table 1}

Physiologic parameters in WT and PI3K $\gamma_{\text {inact }}$ (TG) lines

\begin{tabular}{|c|c|c|c|c|}
\hline Morphometric & $\begin{array}{c}\mathrm{WT} \\
(n=15)\end{array}$ & $\begin{array}{l}20 \text {-fold TG } \\
\qquad(n=9)\end{array}$ & $\begin{array}{l}90 \text {-fold TG } \\
(n=14)\end{array}$ & $\begin{array}{c}\text { 180-fold TG } \\
\quad(n=11)\end{array}$ \\
\hline BW, g & $27.5 \pm 1.2$ & $28.9 \pm 2.0$ & $29.4 \pm 1.2$ & $27.2 \pm 1.5$ \\
\hline Tibial length, mm & $17.54 \pm 0.09$ & $17.54 \pm 0.15$ & $17.83 \pm 0.08$ & $17.15 \pm 0.13$ \\
\hline RV weight, mg & $28.57 \pm 1.61$ & $30.24 \pm 2.49$ & $31.68 \pm 1.62$ & $29.82 \pm 2.07$ \\
\hline LV weight, mg & $96.97 \pm 4.43$ & $101.92 \pm 7.66$ & $102.97 \pm 4.22$ & $102.64 \pm 5.72$ \\
\hline $\mathrm{LWW} / \mathrm{BW}, \mathrm{mg} / \mathrm{g}$ & $3.54 \pm 0.08$ & $3.52 \pm 0.08$ & $3.51 \pm 0.06$ & $3.78 \pm 0.12$ \\
\hline LV/tibial length, $\mathrm{mg} / \mathrm{mm}$ & $5.53 \pm 0.25$ & $5.79 \pm 0.40$ & $5.77 \pm 0.23$ & $5.98 \pm 0.31$ \\
\hline Echocardiographic (conscious) & $(n=10)$ & $(n=6)$ & $(n=7)$ & $(n=7)$ \\
\hline Heart rate, bpm & $613 \pm 13$ & $633 \pm 12$ & $582 \pm 11$ & $598 \pm 12$ \\
\hline LVEDD, mm & $2.99 \pm 0.06$ & $3.15 \pm 0.13$ & $3.09 \pm 0.10$ & $2.99 \pm 0.10$ \\
\hline LVESD, mm & $1.48 \pm 0.04$ & $1.40 \pm 0.13$ & $1.44 \pm 0.09$ & $1.44 \pm 0.04$ \\
\hline $\mathrm{FS}, \%$ & $51 \pm 1$ & $55 \pm 4$ & $53 \pm 2$ & $52 \pm 1$ \\
\hline SEPth, mm & $1.06 \pm 0.04$ & $0.87 \pm 0.05$ & $0.94 \pm 0.07$ & $1.19 \pm 0.05$ \\
\hline PWth, mm & $1.03 \pm 0.06$ & $0.79 \pm 0.05$ & $0.99 \pm 0.07$ & $1.00 \pm 0.65$ \\
\hline Mean Vcfc, circ/s & $3.96 \pm 0.15$ & $4.04 \pm 0.27$ & $4.23 \pm 0.27$ & $3.62 \pm 0.11$ \\
\hline Hemodynamic (anesthetized) & $(n=13)$ & & & $(n=8)$ \\
\hline $\mathrm{LV} d P / d t_{\max }, \mathrm{mmHg} / \mathrm{s}$ & $7,954 \pm 731$ & & & $7,639 \pm 1,052$ \\
\hline $\mathrm{LV} d P / d t_{\min }, \mathrm{mmHg} / \mathrm{s}$ & $6,038 \pm 427$ & & & $5,916 \pm 622$ \\
\hline LVEDP, mmHg & $5.5 \pm 0.6$ & & & $5.1 \pm 0.7$ \\
\hline LVSP, mmHg & $90.4 \pm 3.3$ & & & $87.4 \pm 3.7$ \\
\hline Heart rate, bpm & $415 \pm 7$ & & & $405 \pm 19$ \\
\hline
\end{tabular}

TG, transgenic; RV, right ventricle; LWW, LV weight; bpm, heart beats per minute; LVEDD, LV end-diastolic dimension; LVESD, LV end-systolic dimension; FS, fractional shortening (LVEDD - LVESD)/LVEDD; SEPth, septal wall thickness; PWth, posterior wall thickness; circ/s, circumference/second; mean Vcfc; heart rate-corrected mean velocity of circumferential fiber shortening calculated as FS divided by ejection time multiplied by the square root of the R-R interval; $\mathrm{LV} d P / d t_{\max }$ and $d P / d t_{\min }$, maximum and minimum first derivatives of the LV pressure; LVEDP, LV end-diastolic pressure; LVSP, LV systolic pressure. 

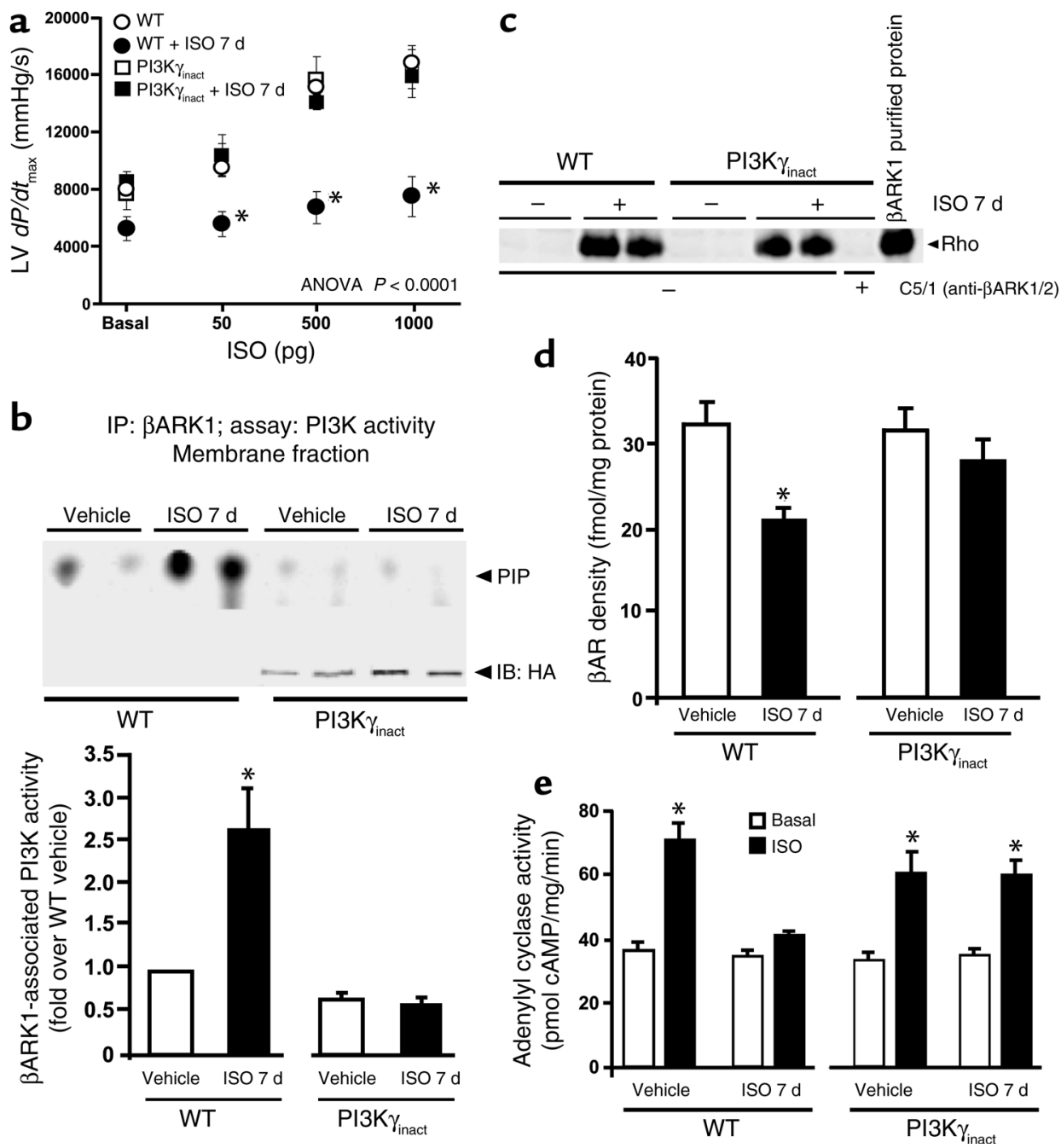

Figure 2

$\mathrm{PI} 3 \mathrm{~K} \gamma$ inact-overexpressing mice do not undergo $\beta$ AR desensitization or downregulation under conditions of chronic catecholamine administration. (a) In vivo hemodynamic studies showing $\beta$ AR responsiveness as monitored by the increase in left ventricular contractility $\left(L V d P / d t_{\text {max }}\right)$ in WT and PI3K $\gamma_{\text {inact }}$ mice following 7 days of ISO (closed circles: $n=9$; closed squares: $n=7$ ) or vehicle (open circles: $n=13$; open squares: $n=8$ ) treatment. ${ }^{*} P<0.0001$ (two-way ANOVA) WT ISO versus PI3K $\gamma_{\text {inact }}$ ISO. (b) $\beta A R K 1$-associated PI3K activity in WT and PI3K $\gamma_{\text {inact }}$ ventricles $(500 \mu \mathrm{g}$ of membrane fraction) following 7 days of ISO $(n=6)$ or vehicle treatment $(n=5-6)$. Values are expressed relative to vehicletreated WT. Immunoblotting the HA-epitope tag $\left(\mathrm{PI} 3 \mathrm{~K} \gamma_{\text {inact }}\right)$ following immunoprecipitation with $\beta$ ARK 1 from $500 \mu \mathrm{g}$ of membrane fraction (upper immunoblot, IB: HA). ${ }^{*}<0.001$ ISO 7 days versus vehicle. (c) In vitro myocardial $\beta A R K 1$ activity measured by rhodopsin (Rho) phosphorylation in WT and PI3K $\gamma_{\text {inact }}$ mice following 7 days of ISO or vehicle treatment. (d) $\beta A R$ density among WT and PI3K $\gamma_{\text {inact }}$ mice following 7 days of ISO administration $(n=6)$ or vehicle treatment $(n=5-6) .{ }^{*} P<0.05$ ISO 7 days versus vehicle. (e) Basal (white bars) and in vitro ISOstimulated (black bars) adenylyl cyclase activity in WT and PI3K $\gamma_{\text {inact }}$ mice following 7 days of ISO $(n=6)$ or vehicle treatment $(n=5-6)$. Adenylyl cyclase activity upon NaF stimulation: $257 \pm 21 \mathrm{pmol} / \mathrm{mg} / \mathrm{min}$ and $244 \pm 18 \mathrm{pmol} / \mathrm{mg} / \mathrm{min}$ for vehicle and ISO 7-day treatment, respectively, in WT; $242 \pm 12 \mathrm{pmol} / \mathrm{mg} / \mathrm{min}$ and $239 \pm 24 \mathrm{pmol} / \mathrm{mg} / \mathrm{min}$ for vehicle and ISO 7-day treatment, respectively, in PI3K $\gamma_{\text {inact }}$ mice. ${ }^{*} P<0.002$ ISO versus basal. $\beta$ ARK1 $(C 5 / 1) \mathrm{mAb}$ is directed against the catalytic site of $\beta$ ARK1 blocking its enzymatic activity.

the physiologically relevant phospholipid, using the specific class I PI3K substrate PtdIns-4,5- $\mathrm{P}_{2}$. Robust total $\mathrm{PI} 3 \mathrm{~K}$ and PI3K $\gamma$ activity was observed in the WT mice, while generation of PIP3 was attenuated in the PI $3 \mathrm{~K} \gamma_{\text {inact }}$ transgenic mice (Figure 1e). Importantly, reduced generation of PIP3 was also observed when $\beta$ ARK1 was immunoprecipitated and assayed for PI3K activity in the PI3K $\gamma_{\text {inact }}$ mice (Figure 1e). To directly assess the association of PI3K with $\beta$ ARK1 in the heart, $\beta$ ARK1 was immunoprecipitated from myocardial lysates and blotted for the coimmunoprecipitating PI3K isoform. PI3K $\gamma$ interacts with $\beta A R K 1$ in the WT mice, and this interaction is increased in the PI $3 \mathrm{~K} \gamma_{\text {inact }}$ transgenic mice due to its association with the overexpressed PI $3 \mathrm{~K} \gamma_{\text {inact }}$ transgene (Figure 1f). In contrast, low levels of PI3K $\alpha$ are found associated with $\beta A R K 1$ in the heart (Figure 1f). Taken together, these data indicate that overexpression of a catalytically inactive PI $3 \mathrm{~K} \gamma$ successfully displaces endogenous active PI3K from $\beta A R K 1$, while having only a modest effect on total cellular PI3K activity.

To determine whether reduced $\beta$ ARK1-associated PI3K $\gamma$ activity would alter the physiologic phenotype of 
the transgenic mice under basal conditions, we assessed cardiac function by echocardiography and cardiac catheterization. No differences were found between WT and any of the PI $3 \mathrm{~K} \gamma_{\text {inact }}$ lines for LV chamber dimensions, fractional shortening, heart rate, or in the LV weight/body weight (LVW/BW) ratios. Furthermore, cardiac catheterization of the WT and 180-fold overexpressing transgenic mice revealed no differences in contractile function ( $\left.\mathrm{LV} d P / d t_{\max }\right)$ or other hemodynamic parameters (Table 1). These data suggest that although a high level of PI $3 \mathrm{~K} \gamma_{\text {inact }}$ overexpression leads to a significant reduction in $\beta$ ARK1-associated PI3K activity, it does not result in any physiologic, morphometric, or hemodynamic changes under unstressed basal conditions (Table 1).

$P I 3 K \gamma_{\text {inact }}$ overexpression prevents isoproterenol-induced $\beta A R$ desensitization and downregulation in vivo. Since we have previously shown a role for PI3K in $\beta A R$ internalization in vitro, we tested the hypothesis that overexpression of PI $3 \mathrm{~K} \gamma_{\text {inact }}$ would prevent $\beta A R$ downregulation in vivo following chronic exposure to high levels of catecholamines. Transgenic mice overexpressing PI3K $\gamma_{\text {inact }}(180$-fold) and their WT littermates were chronically treated with the catecholamine isoproterenol (ISO), for 7 days by osmotic mini-pumps to induce $\beta A R$ downregulation. We then determined $\beta A R$ responsiveness to additional ISO in intact catheterized mice by measuring the first derivative of $L V$ pressure rise, $L V d P / d t$ in individual mice. Compared with treatment with vehicle, chronic ISO treatment resulted in a substantial loss of catecholamine responsiveness in WT mice (Figure 2a). In marked

\section{Figure 3}

$\beta A R K 1-m e d i a t e d$ PI3K recruitment leads to desensitization and downregulation of $\beta$ ARs. (a) BARK1-associated PI3K activity in WT and $\mathrm{PI} 3 \mathrm{~K} \gamma_{\text {inact }}$ ventricles $(500 \mu \mathrm{g}$ of membrane fraction) following 12 hours, 24 hours, 3 days, and 5 days of ISO administration. (b) In vitro ISO-stimulated adenylyl cyclase activity represented as the fold increase over basal level in WT (white bars) and $\mathrm{PI} 3 \mathrm{~K} \gamma_{\text {inact }}$ (black bars) mice following 12 hours, 24 hours, 3 days, and 5 days of chronic ISO administration. (c) $\beta A R$ density among WT and $\mathrm{PI} 3 \mathrm{~K} \gamma_{\text {inact }}$ mice following 12 hours, 24 hours, 3 days, and 5 days of ISO infusion. (d) $\beta A R K 1$-associated PI3K activity measured by the ability to in vitro phosphorylate Ptdlns-4,5- $\mathrm{P}_{2}$ as a substrate to generate Ptdlns-3,4,5- $\mathrm{P}_{3}$ in WT and $\mathrm{PI} 3 \mathrm{~K} \gamma_{\text {inact }}$ ventricles $(500 \mu \mathrm{g}$ of membrane fraction) following 5 days of ISO administration. ${ }^{*} P<0.05$ WT ISO treated versus WT vehicle. ${ }^{\dagger} P<0.05$ WT ISO versus PI3K $\gamma_{\text {inact }}$ ISO at same time point. Sub, substrate. contrast, treated PI3K $\gamma_{\text {inact }}$ mice showed normal contractile responses to catecholamines, indicating normal $\beta A R$ sensitivity. Chronic ISO treatment resulted in a similar $20 \%$ increase in the LVW/BW ratios of both WT and transgenic mice (WT: vehicle $3.5 \pm 0.1 \mathrm{mg} / \mathrm{g}$, ISO $4.3 \pm 0.1 \mathrm{mg} / \mathrm{g} ; \mathrm{PI} 3 \mathrm{~K} \gamma_{\text {inact }}$ : vehicle $3.4 \pm 0.1 \mathrm{mg} / \mathrm{g}$, ISO $4.1 \pm 0.1 \mathrm{mg} / \mathrm{g}, P=\mathrm{NS})$. Thus, overexpression of $\mathrm{PI} 3 \mathrm{~K} \gamma_{\text {inact }}$ in the heart preserves $\beta \mathrm{AR}$ sensitivity under conditions of excess catecholamine levels, without affecting growth responses.

To determine whether chronic ISO administration reduces $\beta$ ARK1-associated PI3K activity in myocardial membranes, WT and PI $3 \mathrm{~K} \gamma_{\text {inact }}$ mice were treated with ISO for 7 days. A robust, 2.6-fold increase in $\beta$ ARK1associated PI3K activity was observed in WT mice following chronic ISO treatment (Figure 2b). This effect was completely abolished in the transgenic mice overexpressing PI3K $\gamma_{\text {inact }}$ (Figure $2 \mathrm{~b}$ ), despite the fact that $\mathrm{PI} 3 \mathrm{~K} \gamma_{\text {inact }}$ protein was recruited to the plasma membrane (Figure 2b; immunoblotting [IB]: HA). Cytosolic $\beta A R K 1$ expression was also increased with chronic ISO treatment in the hearts of both WT and PI $3 \mathrm{~K} \gamma_{\text {inact }}$ mice a

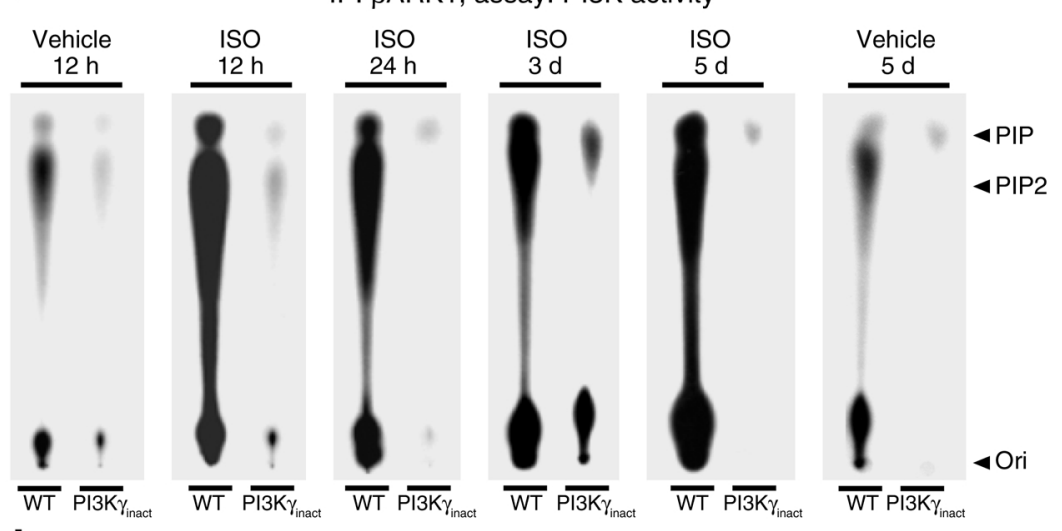

b
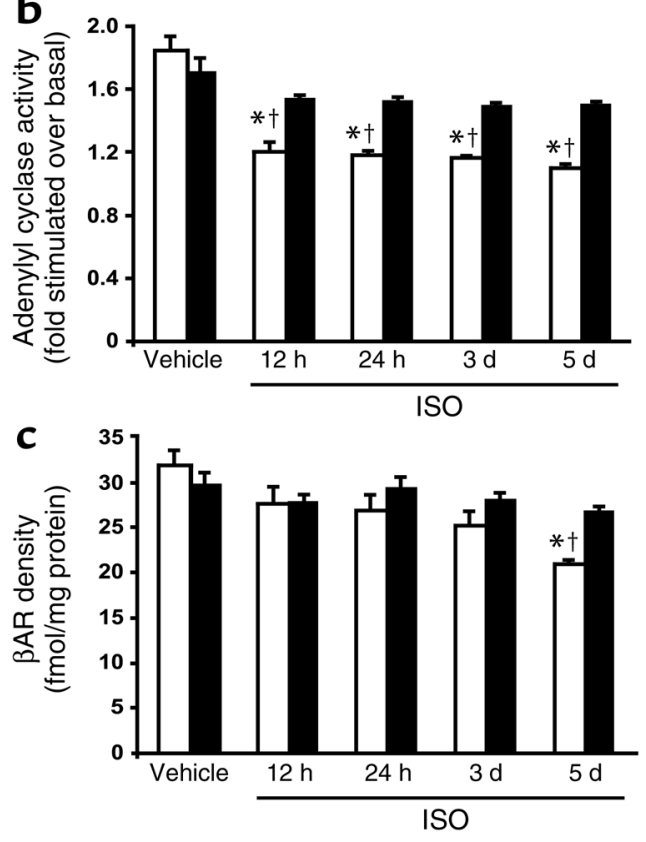

d IP: $\beta A R K 1$ Assay: PI3K activity Sub: Ptdlns-4,5- $\mathrm{P}_{2}$

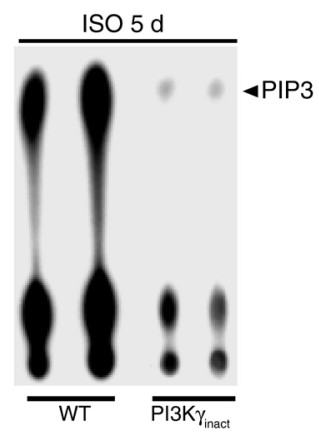



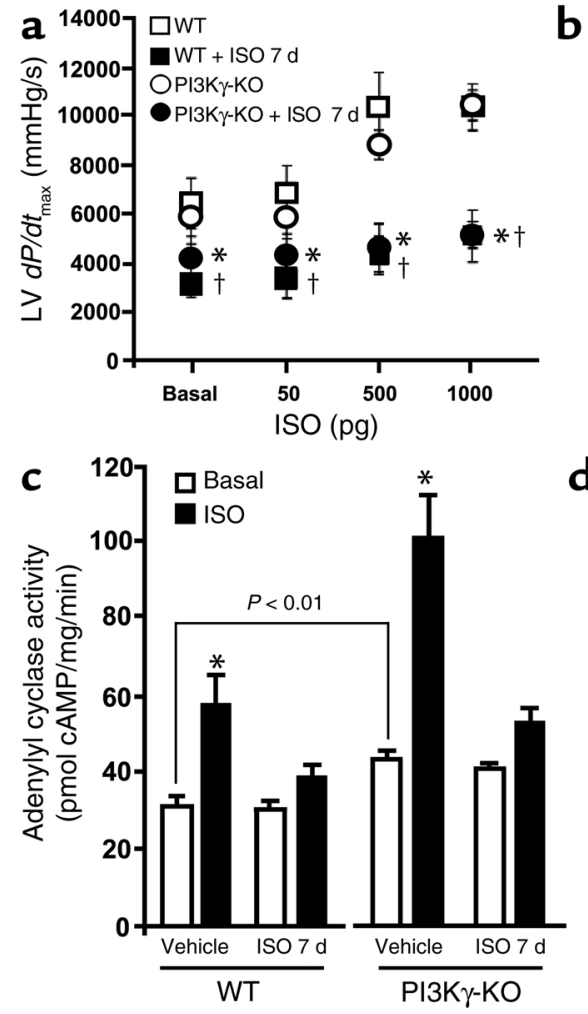

e

BARK1-associated PI3K IP: $\beta$ ARK1; assay: PI3K

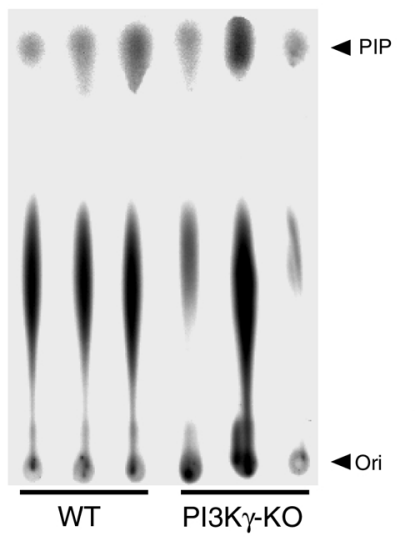

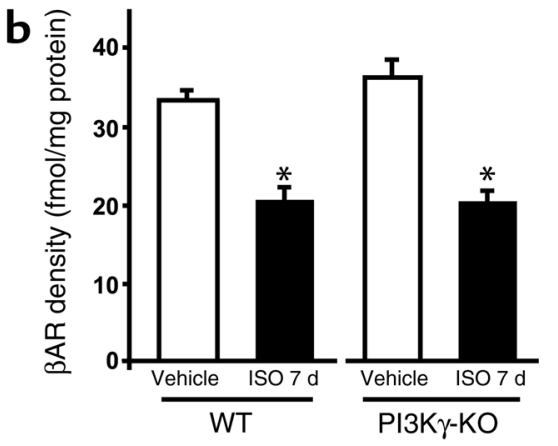

d

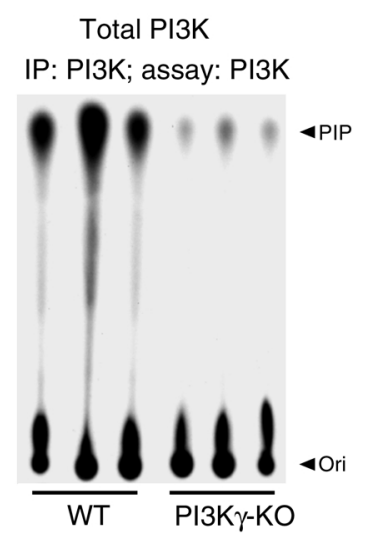

g BARK1-associated PI3K IP: $\beta A R K 1$; assay: PI3K

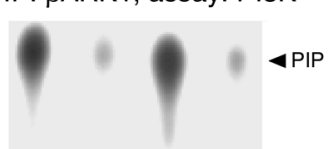

IP: $\beta A R K 1$; IB: PI3K $\gamma$

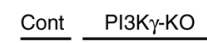

IP: $\beta A R K 1 ;$ IB: PI3K $\alpha$

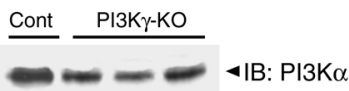

\section{Figure 4}

Preservation of $\beta A R$ sensitivity in $\mathrm{PI} 3 \mathrm{~K} \gamma_{\text {inact }}$ mice is due to the displacement of PI3K from $\beta A R K 1$. (a) In vivo hemodynamic studies of $\beta A R$ responsiveness (increase in LV $\left.d P / d t_{\max }\right)$ following 7 days of ISO (closed circles: $n=7$; closed squares: $n=7$ ) or vehicle (open circles: $n=5$; open squares: $n=5)$ treatment. ${ }^{*} P<0.0001$ (ANOVA) PI3K $\gamma$-KO ISO 7 days versus $\mathrm{PI} 3 \mathrm{~K} \gamma-\mathrm{KO}$ vehicle. ${ }^{\dagger} P<0.0001 \mathrm{WT}$ ISO 7 days versus WT vehicle. (b) $\beta A R$ density following 7 days of ISO $(n=6)$ or vehicle $(n=4)$ treatment. ${ }^{*} P<0.001$ ISO versus vehicle. (c) Basal (white bars) and in vitro ISO-stimulated (black bars) adenylyl cyclase activity following 7 days of ISO $(n=6-8)$ or vehicle treatment $(n=8)$. Adenylyl cyclase activity upon $\mathrm{NaF}$ stimulation: $179.0 \pm 5.7 \mathrm{pmol} / \mathrm{mg} / \mathrm{min}$ and $149.9 \pm 4.8 \mathrm{pmol} / \mathrm{mg} / \mathrm{min}$ for vehicle and ISO, respectively, for 7 days of treatment in WT; $325.2 \pm 7.5 \mathrm{pmol} / \mathrm{mg} / \mathrm{min}$ and $230.3 \pm 5.6 \mathrm{pmol} / \mathrm{mg} / \mathrm{min}$ for vehicle and ISO, respectively, for 7 days treatment in $\mathrm{PI} 3 \mathrm{~K} \gamma-\mathrm{KO}$ mice. ${ }^{*} P<0.001$ ISO versus basal. (d) Total PI3K activity in WT $(n=6)$ and $\mathrm{PI} 3 \mathrm{~K} \gamma-\mathrm{KO}$ mice $(n=6)$. (e) BARK1associated PI3K activity from LV extracts of $\mathrm{WT}(n=6)$ and $\mathrm{PI} 3 \mathrm{~K} \gamma-\mathrm{KO}(n=6)$ mice. $(\mathrm{f})$ $\beta A R K 1$-associated PI3K activity in the presence of wortmannin, a selective PI3K inhibitor. (g) Immunoblotting for PI3K $\gamma$ and $\mathrm{PI} 3 \mathrm{~K} \alpha$ following immunoprecipitation with $\beta A R K 1$. Cont (plus control), immunoprecipitation of $\mathrm{PI} 3 \mathrm{~K} \alpha$ or $\mathrm{PI} 3 \mathrm{~K} \gamma$ with its respective $A b$ and immunoblotted for $\mathrm{PI} 3 \mathrm{~K} \alpha$ or $\mathrm{PI} 3 \mathrm{~K} \gamma$. hearts (data not shown). Therefore, overexpression of PI3K $\gamma_{\text {inact }}$ displaces active endogenous PI3K from $\beta A R K 1$, leading to the translocation of inactive PI3K by $\beta A R K 1$ to the myocardial membrane under conditions of agonist stimulation.

Translocation of $\beta A R K 1$ depends on dissociated $G_{\beta \gamma}$ subunits from heterotrimeric $\mathrm{G}$ proteins (22). Since PI3K $\gamma$ binds $\mathrm{G}_{\beta \gamma}$ subunits, we tested whether overexpression of PI3K $\gamma_{\text {inact }}$ alters the membrane recruitment of $\beta A R K 1$. Membrane and cytosolic extracts from WT and PI $3 K_{\text {inact }}$ transgenic hearts were measured for their capacity to phosphorylate the GPCR rhodopsin. Membrane extracts from chronic ISO-treated hearts showed a similar increase in $\beta A R K 1$ activity (Figure $2 c$ ) that was abolished by prein-

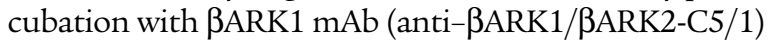

(Figure 2c) (23). These data demonstrate that overexpression of $\mathrm{PI} 3 \mathrm{~K} \gamma_{\text {inact }}$ does not alter the function or recruitment of $\beta A R K 1$ to myocardial membranes.

To determine whether inhibition of locally generated PtdIns-3,4,5- $\mathrm{P}_{3}$ within the plasma membrane diminishes the degree of $\beta A R$ downregulation and desensitization that occurs with chronic ISO treatment, we measured $\beta A R$ density and adenylyl cyclase activity in crude myocardial membrane preparations from WT and transgenic mouse hearts after 7 days of chronic ISO treatment. $\beta A R$ density was reduced $33 \%$ in chronic ISO-treated WT hearts compared with vehicle-treated WT hearts (Figure 2d). In contrast, no significant decrease in $\beta A R$ density occurred in the ISO-treated $\mathrm{PI} 3 \mathrm{~K} \gamma_{\text {inact }}$ hearts compared with vehicle-treated $\mathrm{PI} 3 \mathrm{~K} \gamma_{\text {inact }}$ 
hearts (Figure 2d). Furthermore, overexpression of $\mathrm{PI} 3 \mathrm{~K} \gamma_{\text {inact }}$ completely preserved adenylyl cyclase activity following chronic ISO treatment compared with WT (Figure 2e). Taken together, these data show that under conditions of high levels of circulating catecholamines, overexpression of PI $3 \mathrm{~K} \gamma_{\text {inact }}$ in the heart preserves in vivo $\beta A R$ responsiveness by preventing the downregulation and desensitization of myocardial $\beta$ ARs.

To determine the time course of $\beta$ ARK1-mediated PI3K recruitment, receptor desensitization, and downregulation, WT and PI $3 \mathrm{~K} \gamma_{\text {inact }}$ transgenic mice were treated with isoproterenol by mini-osmotic pump for 12 hours, 24 hours, 3 days, and 5 days. Significant $\beta$ ARK1-associated PI3K activity was observed in membrane fractions of WT mice within 12 hours of ISO and was sustained throughout the entire time course of ISO administration (Figure 3a). In contrast, $\beta A R K 1-$ mediated PI3K recruitment was prevented in the PI3K $\gamma_{\text {inact }}$ transgenic mice over the same time period (Figure 3a). Vehicle treatment had no effect on the recruitment of PI3K (Figure 3a and Figure 2b). $\beta A R$ receptor desensitization as measured by diminished ISO-stimulated membrane adenylyl cyclase activity also occurred within 12 hours of ISO administration (Figure $3 \mathrm{~b}$ ), which was also prevented in the $\mathrm{PI} 3 \mathrm{~K} \gamma_{\text {inact }}$ transgenic mice (Figure 3b). As opposed to the early events of PI3K recruitment and $\beta A R$ desensitization, downregulation of $\beta$ ARs did not occur until 3 days of ISO administration and was significantly reduced $30 \%$ upon 5 days of chronic catecholamine administration (Figure 3c). Importantly, no significant changes in $\beta A R$ density occurred in the $\mathrm{PI} 3 \mathrm{~K} \gamma_{\text {inact }}$ transgenic mice throughout the entire ISO administration time course (Figure $3 c$ ).

The ability of $\beta$ ARK1-associated PI3K to generate PIP3 was measured using the in vitro substrate PtdIns-4,5- $\mathrm{P}_{2}$ from the membranes of 5-day ISO-treated WT and PI $3 \mathrm{~K} \gamma_{\text {inact }}$ mice. Robust PIP3 production was observed with the $\beta A R K 1$ immunoprecipitates from the WT mice, which was completely blocked in the PI3K $\gamma_{\text {inact }}$ transgenic mice (Figure 3d). These data show that overexpression of PI3K $\gamma_{\text {inact }}$ transgene displaces endogenous PI3K from $\beta$ ARK1 and that $\beta$ ARK1-mediated recruitment of PI3K and receptor desensitization occurs early with agonist stimulation followed by receptor downregulation.

PI $3 K \gamma_{\text {inact }}$ overexpression displaces all endogenous interacting PI3K isoforms from $\beta A R K 1$. An important issue is whether the preservation of $\beta A R$ functions with chronic ISO in the transgenic mice occurred because of the displacement of endogenous PI3K from the $\beta$ ARK1/PI3K complex, as we postulate, or due to a generalized reduction in cellular PI3K $\gamma$ activity. To test the latter possibility, we used PI3K $\gamma$ knockout (PI3K $\gamma$-KO) mice that were homozygous for the PI3K $\gamma$ null allele. Mini-osmotic pumps containing ISO or vehicle were implanted in both WT and PI3K $\gamma$-KO mice and hemodynamic studies performed 7 days later. ISO induced a brisk increase in $\mathrm{LV} d P / d t_{\max }$ in both the vehicle-treated WT and PI3K $\gamma$-KO mice (Figure 4a), whereas in vivo $\beta A R$ responsiveness was severely attenuated in chronically ISO-treated PI3K $\gamma$-KO and WT mice. The difference in basal $\mathrm{LV} d P / d t_{\max }$ for WT control of PI3K $\gamma$-KO mice and WT controls of PI3K $\gamma_{\text {inact }}$ transgenic mice is likely attributed to the different genetic backgrounds of these mice and is consistent with our previous studies $(24,25)$. Importantly, a similar response to ISO is observed for the two inbred WT strains with a twofold increase in $\mathrm{LV} d P / d t_{\max }$ at maximal doses of ISO.

We further evaluated $\beta A R$ density and adenylyl cyclase activity in crude myocardial membrane preparations from WT and PI3K $\gamma$-KO mice, and $\beta$ AR densi-
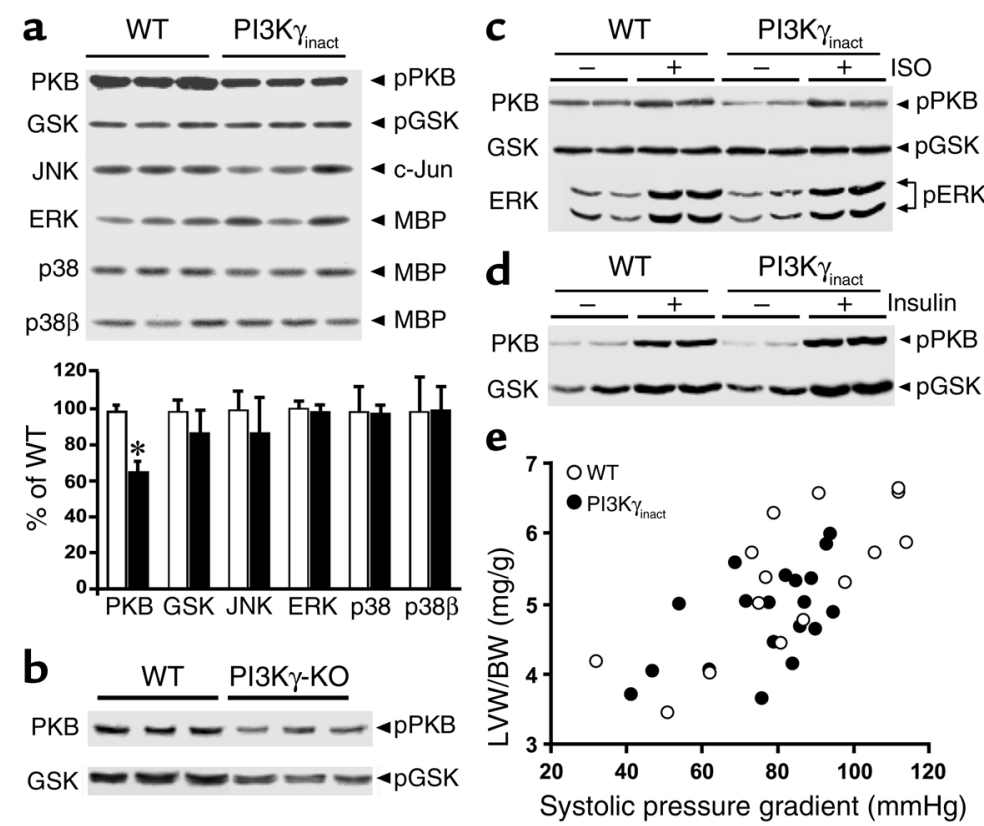

Figure 5

Cardiac-specific overexpression of PI3K $\gamma_{\text {inact }}$ does not alter downstream PI3K signaling. (a) JNK, ERK, p38, and p38ß MAPK activities from $1 \mathrm{mg}$ left ventricular myocardial extracts of WT and PI $3 \mathrm{~K} \gamma_{\text {inact }}$ mice under unstimulated conditions. Myocardial extracts $(100 \mu \mathrm{g})$ from WT and PI $3 \mathrm{~K} \gamma_{\text {inact }}$ mice immunoblotted for PPKB and pGSK White bars, WT; black bars, PI3K $\gamma_{\text {inact. }}{ }^{*} P<0.01 \mathrm{PI} 3 \mathrm{~K} \gamma_{\text {inact }}$ versus WT. (b) Myocardial extracts from WT and PI3K $\gamma-\mathrm{KO}$ mice immunoblotted for $\mathrm{pPKB}$ and $\mathrm{pGSK}$. (c and $\mathbf{d}$ ) PPKB, PGSK, and phospho-ERK (pERK) immunoblots from $100 \mu \mathrm{g}$ of myocardial extract of WT and PI3K $\gamma_{\text {inact }}$ mice following 7 days of ISO treatment (c) and upon insulin stimulation (d). (e) Hypertrophic response to pressure overload induced by TAC measured as a ratio of left ventricular weight (LWW/BW) is plotted against the systolic pressure gradient produced by transverse aortic constriction for each WT (open circles: $n=15$ ) and PI3K $\gamma_{\text {inact }}$ (closed circles: $n=19$ ) mouse. Mean pressure gradient between the groups was similar, WT $83.3 \pm 6.1$ and $\mathrm{PI} 3 \mathrm{~K} \gamma_{\text {inact }} 77.0 \pm 3.6 \mathrm{mmHg}$. JNK, c-Jun $\mathrm{NH}_{2}$-terminal kinase; ERK, extracellular signal-regulated kinase; PKB, protein kinase B; GSK, glycogen synthase kinase B; MBP, myelin basic protein. 


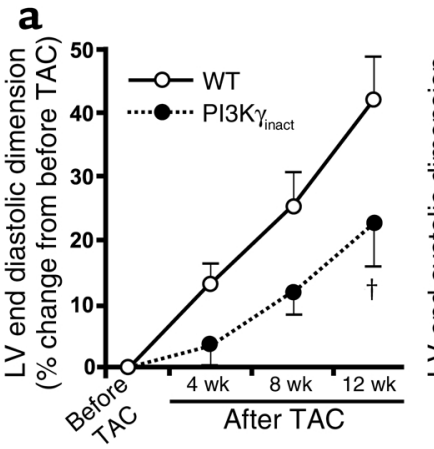

b

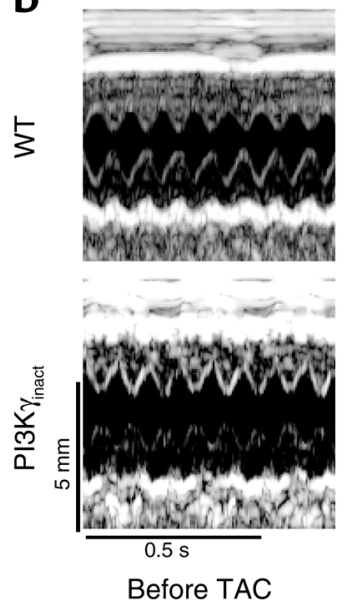

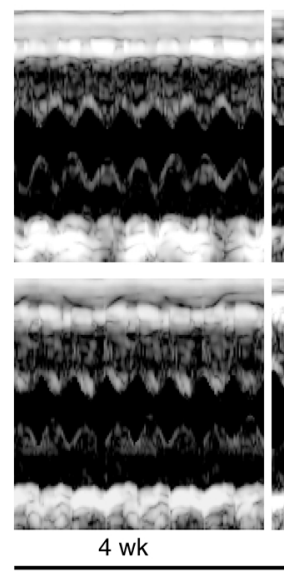
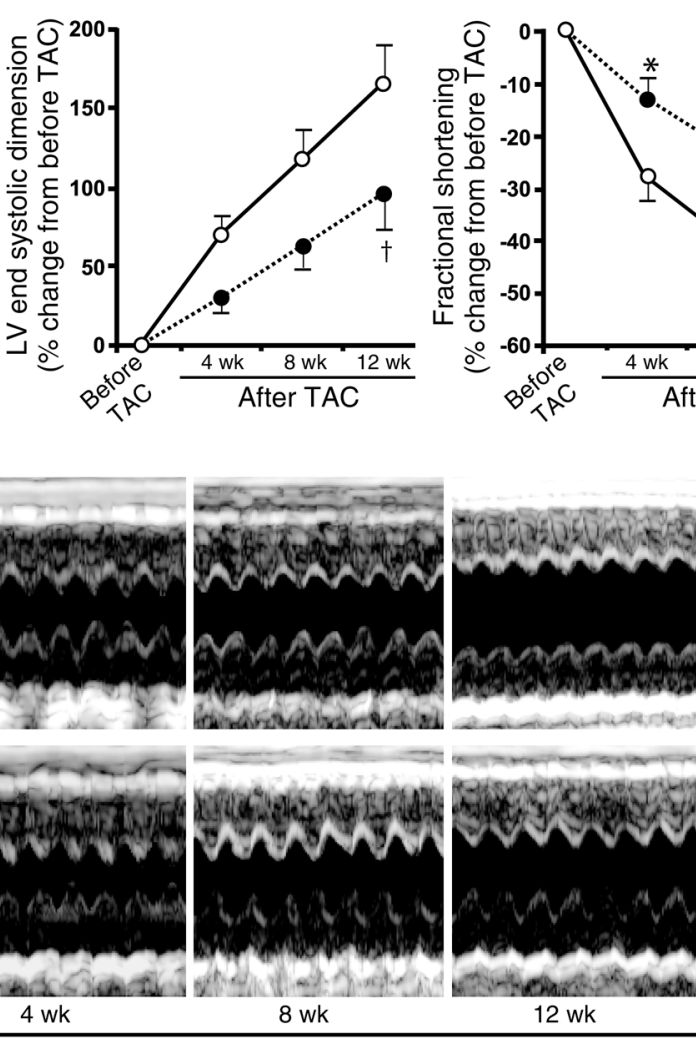

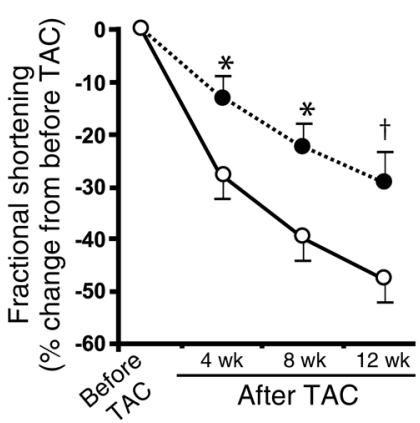

C

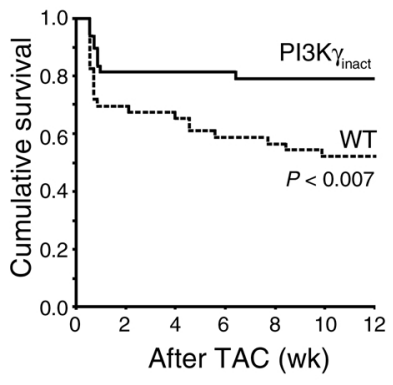

d BARK1-associated PI3K IP: $\beta A R K 1$; assay: PI3k

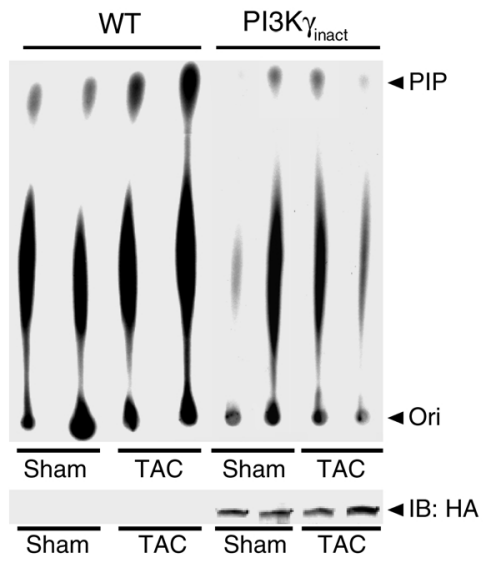

Figure 6

PI3K $\gamma_{\text {inact }}$ overexpression delays development of cardiac failure following chronic pressure overload induced by TAC. (a) Percentage of change in LV end diastolic dimension, LV end systolic dimension, and fractional shortening in WT $(n=22)$ and PI3K $\gamma_{\text {inact }}(n=23)$ mice measured by serial echocardiography at indicated time intervals after TAC. ${ }^{*} P<0.05$ or ${ }^{t} P<0.01$ for PI $3 \mathrm{~K} \gamma$ inact versus WT at the same point. (b) Representative serial echocardiography in conscious WT and PI3K $\gamma_{\text {inact }}$ mice with chronic pressure overload. (c) Kaplan-Meier survival analysis in $\mathrm{WT}(n=46)$ and $\mathrm{PI} 3 \mathrm{~K} \gamma_{\text {inact }}$ mice $(n=48)$ after surgery $(\mathrm{TAC}) . P<0.007, \mathrm{PI} 3 \mathrm{~K} \gamma_{\text {inact }}$ TAC versus WT TAC. (d) $\beta$ ARK 1 -associated PI3K activity in membrane fractions from hearts of WT and PI3K $\gamma_{\text {inact }}$ mice $(500 \mu \mathrm{g})$ (upper). Immunoblotting for the HA-epitope (PI3K $\left.\gamma_{\text {inact }}\right)$ following immunoprecipitation with $\beta$ ARK1 (lower).

ty was equally reduced approximately $40 \%$ in chronic ISO-treated WT and PI3K $\gamma$-KO hearts (Figure 4b) compared with the vehicle-treated hearts. Despite the increase in basal adenylyl cyclase activity in the PI3K $\gamma$ KO mice (Figure 4c), as previously described (9), chronic ISO treatment resulted in marked desensitization to an extent similar to the WT mice (Figure 4c). Taken together, these data show that under conditions of high levels of circulating catecholamines absence of PI3K $\gamma$ does not prevent $\beta$ AR downregulation or receptor desensitization, in marked contrast to the results obtained in the PI $3 \mathrm{~K} \gamma_{\text {inact }}$ transgenic mice.

The above PI3K $\gamma$-KO studies suggest that $\beta$ ARK1 may be interacting with other PI3K isoforms to promote $\beta A R$ internalization, a finding we have shown previously in vitro for PI3K $\alpha(10)$. To demonstrate that $\beta$ ARK1 interacts with other PI3K isoforms in the heart, total and $\beta A R K 1$-associated PI3K activity was measured from the myocardial lysates of WT and PI3K $\gamma$-KO mice. PI3K $\gamma$ activity was not detectable in the knockout mice, confirming the null phenotype (data not shown), while total PI3K activity was markedly reduced (Figure 4d).
We found the level of $\beta A R K 1$-associated PI3K activity in the hearts of PI3K $\gamma$-KO mice, however, to be identical to that of the WT hearts (Figure 4, e and f), however, and this lipid kinase activity was wortmannin sensitive (Figure 4f). To test directly for the interacting PI3K isoform with $\beta A R K 1$ in the PI3K $\gamma$-KO mice, $\beta A R K 1$ was immunoprecipitated from clarified myocardial lysates and blotted for both PI3K $\alpha$ and PI3K $\gamma$. As shown in Figure $4 \mathrm{~g}, \mathrm{PI} 3 \mathrm{~K} \alpha$ is the only isoform that coimmunoprecipitates with $\beta A R K 1$ in the PI3K $\gamma$-KO mice. Taken together, these data show that interrupting the $\beta A R K 1 / P I 3 K$ interaction in the heart in vivo preserves $\beta A R$ function in response to chronically elevated levels of circulating catecholamines. These data also show that in the absence of PI3K $\gamma, \beta A R K 1$ can interact with other PI3K isoform(s) in vivo to promote downregulation and desensitization of $\beta$ ARs.

Cardiac-specific overexpression of PI3K $\gamma_{\text {inact }}$ does not alter downstream PI3K signaling or development of cardiac bypertrophy. Since PI3K plays an important role in regulating cellular signaling, we wanted to exclude the possibility that overexpression of $\mathrm{PI} 3 \mathrm{~K} \gamma_{\text {inact }}$ altered the activity of 
downstream signaling pathways. Under unstimulated conditions, no difference in activity was observed for all the three major MAPK pathways (ERK, JNK, and $\mathrm{p} 38 / \mathrm{p} 38 \beta)$ between the PI3K $\gamma_{\text {inact }}$ mice and their WT littermate controls (Figure 5a). While PI3K $\gamma_{\text {inact }}$ mice showed a significant decrease in $\mathrm{PPKB}$, this decrease did not change the phosphorylation status of the immediate downstream enzyme glycogen synthase kinase (GSK3) (Figure 5a). In contrast to the findings in the PI3K $\gamma_{\text {inact }}$ mice, both $\mathrm{pPKB}$ and pGSK were reduced in the PI $3 \mathrm{~K} \gamma-\mathrm{KO}$ mice in the unstressed basal state (Figure $5 \mathrm{~b}$ ). We further determined whether overexpression of PI $3 \mathrm{~K} \gamma_{\text {inact }}$ transgene in the mice would affect immediate downstream signaling molecules like PKB, GSK3, and ERK following either GPCR or growth factor stimulation. Chronic ISO administration for 7 days showed a similar increase in both pPKB and pERK in the PI3K $\gamma_{\text {inact }}$ mice compared with the WT and had no effect on the level of pGSK3 (Figure 5c). Moreover, acute insulin administration led to significant increase of PPKB and pGSK levels in the PI $3 \mathrm{~K} \gamma_{\text {inact }}$ transgenic mice, also similar to the increase observed in the hearts of WT mice (Figure 5d). These studies, taken together, show that overexpression of PI $3 \mathrm{~K} \gamma_{\text {inact }}$ transgene does not interfere with the downstream signaling of GPCR or receptor tyrosine kinases.

Since acute agonist stimulation was not altered in $\mathrm{PI} 3 \mathrm{~K} \gamma_{\text {inact }}$ mice, we wanted to determine whether overexpression of the $\mathrm{PI} 3 \mathrm{~K} \gamma_{\text {inact }}$ transgene alters the response of the heart to a pleiotropic stimulus such as pressure overload-induced cardiac hypertrophy. The hypertrophic response after 7 days of pressure overload was measured as the index of LVW/BW and plotted against the systolic pressure gradient. Importantly, $\mathrm{LVW} / \mathrm{BW}$ for individual WT and PI $3 \mathrm{~K} \gamma_{\text {inact }}$ mice across a wide range of systolic pressure gradients was not different, indicating intact hypertrophic signaling pathways in the PI $3 \mathrm{~K} \gamma_{\text {inact }}$ transgenic mice (Figure $5 \mathrm{e}$ ). As a group there was a similar $150 \%$ increase in $\mathrm{LV} / \mathrm{BW}$ after
7 days of TAC (pre-TAC WT, $3.35 \pm 0.52 \mathrm{mg} / \mathrm{g}$, and $\mathrm{PI} 3 \mathrm{~K} \gamma_{\text {inact }}, 3.31 \pm 0.46 \mathrm{mg} / \mathrm{g}$, to post-TAC WT, $5.33 \pm 1.00$ $\mathrm{mg} / \mathrm{g}$, and $\left.\mathrm{PI} 3 \mathrm{~K} \gamma_{\text {inact }}, 4.83 \pm 0.69 \mathrm{mg} / \mathrm{g}\right)$. Taken together, these data show that overexpression of PI3K $\gamma_{\text {inact }}$ does not inhibit the activation of downstream signaling pathways in the heart in response to multiple extracellular stimuli.

Cardiac-specific overexpression of PI $3 K \gamma_{\text {inact }}$ preserves cardiac function under conditions of chronic pressure overload. PI3K $\gamma_{\text {inact }}$ mice and their WT littermates underwent TAC and were subsequently followed for 12 weeks. Serial echocardiography showed progressive LV enlargement and deterioration in cardiac function in the WT littermates (Figures 6, a and b) (Table 2). In contrast, PI $3 \mathrm{~K} \gamma_{\text {inact }}$ overexpression significantly delayed the development of cardiac dysfunction and dilatation over the same time period following chronic pressure overload (Figures 6, a and b). Furthermore, survival of PI3K $\gamma_{\text {inact }}$ mice after TAC was significantly greater compared with the WT mice (mean survival PI3K $\gamma_{\text {inact }} 68 \pm 4$ days and WT $52 \pm 5$ days, $P<0.007$; Figure $6 c$ ), consistent with amelioration of the cardiac phenotype. Transgenic and WT littermate mice used for studies in Table 1 were inbred on a DBA background, while mice used for TAC studies (Table 2) were inbred on a C57BL/ 6 background. Small differences in basal percentage of fractional shortening between Table 1 and Table 2 are likely attributed to differences in the genetic background.

Because PI3K $\gamma$ is recruited to the membrane by $\beta A R K 1$, we determined $\beta A R K 1$-associated PI3K activity in the membrane fractions of sham and TAC hearts. The increase in the $\beta A R K 1$-associated PI3K activity in the TAC WT hearts was abolished in the TAC PI3K $\gamma_{\text {inact }}$ mice (Figure $6 \mathrm{~d}$ ) and was replaced by inactive PI $3 \mathrm{~K} \gamma_{\text {inact }}$ protein (Figure 6d; IB: HA). Importantly, blocking the recruitment of active PI3K to the membrane prevented the downregulation of $\beta$ ARs in the cardiac membranes of TAC PI $3 \mathrm{~K} \gamma_{\text {inact }}$ mice in contrast with the TAC WT

Table 2

Echocardiographic, morphometric, and hemodynamic data from WT and PI3K $\gamma_{\text {inact }}$ mice under conditions of pressure overload induced by TAC

\begin{tabular}{|c|c|c|c|c|c|c|c|c|}
\hline & \multicolumn{4}{|c|}{$\mathrm{WT}(n=22)$} & \multicolumn{4}{|c|}{$\mathrm{PI} 3 \mathrm{~K} \gamma$ inact $(n=23)$} \\
\hline & \multirow[t]{2}{*}{ Before } & \multicolumn{3}{|c|}{ After } & \multirow[t]{2}{*}{ Before } & \multicolumn{3}{|c|}{ After } \\
\hline & & 4 Weeks & 8 Weeks & 12 Weeks & & 4 Weeks & 8 weeks & 12 weeks \\
\hline Heart rate, bpm & $668 \pm 6$ & $649 \pm 5$ & $651 \pm 6$ & $655 \pm 8$ & $654 \pm 9$ & $655 \pm 6$ & $657 \pm 6$ & $647 \pm 9$ \\
\hline LVEDD, mm & $3.01 \pm 0.05$ & $3.40 \pm 0.12$ & $3.79 \pm 0.19^{C}$ & $4.30 \pm 0.24^{C}$ & $3.02 \pm 0.04$ & $3.11 \pm 0.08$ & $3.37 \pm 0.10$ & $3.69 \pm 0.19^{B}$ \\
\hline LVESD, mm & $1.14 \pm 0.05$ & $1.94 \pm 0.16$ & $2.47 \pm 0.24^{C}$ & $3.03 \pm 0.30^{c}$ & $1.11 \pm 0.04$ & $1.42 \pm 0.11$ & $1.77 \pm 0.15$ & $2.16 \pm 0.26^{\mathrm{A}, \mathrm{C}}$ \\
\hline $\mathrm{FS}, \%$ & $62 \pm 1$ & $45 \pm 3^{C}$ & $38 \pm 3^{C}$ & $33 \pm 3^{C}$ & $63 \pm 1$ & $55 \pm 2$ & $49 \pm 3^{A, C}$ & $45 \pm 4^{\mathrm{A}, \mathrm{C}}$ \\
\hline SEPth, mm & $0.77 \pm 0.02$ & $1.07 \pm 0.04^{C}$ & $1.01 \pm 0.04 \mathrm{C}$ & $0.98 \pm 0.05^{\mathrm{B}}$ & $0.76 \pm 0.02$ & $1.12 \pm 0.03^{c}$ & $1.11 \pm 0.04^{C}$ & $1.06 \pm 0.05^{C}$ \\
\hline PWth, mm & $0.73 \pm 0.02$ & $1.00 \pm 0.03^{C}$ & $1.01 \pm 0.04^{C}$ & $0.97 \pm 0.06^{C}$ & $0.74 \pm 0.01$ & $1.08 \pm 0.03^{C}$ & $1.10 \pm 0.04^{C}$ & $1.04 \pm 0.05^{C}$ \\
\hline $\begin{array}{l}\text { Mean Vcfc, } \\
\text { circ/s }\end{array}$ & $4.28 \pm 0.10$ & $3.04 \pm 0.20^{C}$ & $2.50 \pm 0.19^{c}$ & $2.14 \pm 0.19^{C}$ & $4.36 \pm 0.08$ & $3.74 \pm 0.16$ & $3.32 \pm 0.19^{\mathrm{A}, \mathrm{C}}$ & $2.96 \pm 0.24^{\mathrm{A}, \mathrm{C}}$ \\
\hline BW, g & $27.5 \pm 1.2$ & & & $26.6 \pm 1.0$ & $29.0 \pm 1.0$ & & & $28.9 \pm 1.2$ \\
\hline LWW/BW, mg/g & & & & $6.94 \pm 0.30$ & & & & $5.70 \pm 0.29^{A}$ \\
\hline TSPG, mmHg & & & & $71.5 \pm 3.3$ & & & & $90.4 \pm 6.3^{A}$ \\
\hline
\end{tabular}

TSPG, trans-stenotic systolic pressure gradient as the difference between right carotid and left axillary artery systolic pressures. ${ }^{A} P<0.01, P I 3 K \gamma_{\text {inact }}$ versus $W T$ at same point; ${ }^{B} P<0.01 ;{ }^{C} P<0.001$ versus before TAC in same group. Two-way repeated measures ANOVA was used in the analysis of the data. 


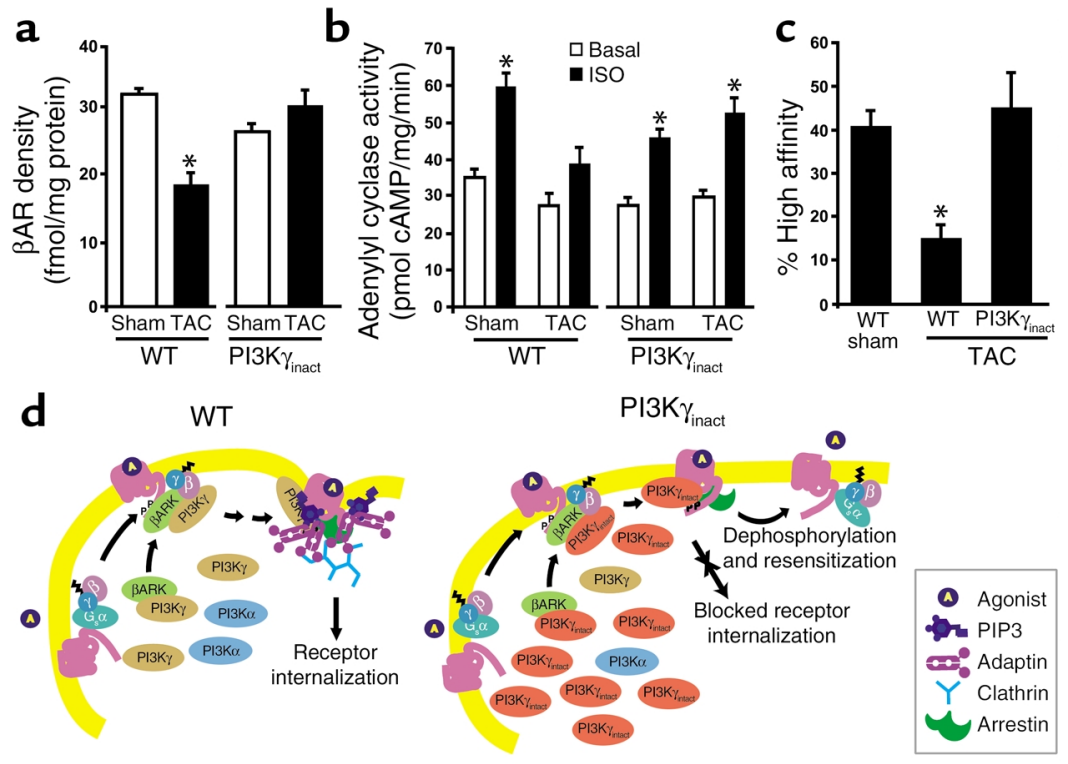

Figure 7

Competitive displacement of endogenous active PI3K by PI3K $\gamma_{\text {inact }}$ from $\beta$ ARK1 prevents $\beta A R$ dysfunction following 12 weeks of chronic pressure overload. (a) $\beta A R$ density among WT and PI3K $\gamma_{\text {inact }}$ mice (WT and PI3K $\gamma_{\text {inact }}$ sham: $n=4$; TAC: $\left.n=4\right) .{ }^{*} P<0.005$ WT TAC versus WT sham. (b) Basal (white bars) and ISO-stimulated (black bars) adenylyl cyclase activity in membrane fractions from WT $(n=8-10)$ and $\mathrm{PI} 3 \mathrm{~K} \gamma_{\text {inact }}(n=7-8)$ hearts. Adenylyl cyclase activity upon NaF stimulation: $185 \pm 8 \mathrm{pmol} / \mathrm{mg} / \mathrm{min}$ for WT-sham; $128 \pm 10 \mathrm{pmol} / \mathrm{mg} / \mathrm{min}$ for WTTAC; $151 \pm 6 \mathrm{pmol} / \mathrm{mg} / \mathrm{min}$ for PI3K $\gamma_{\text {inact }}$-sham; $162 \pm 10 \mathrm{pmol} / \mathrm{mg} / \mathrm{min}$ for $\mathrm{PI} 3 \mathrm{~K} \gamma_{\text {inact }}$-TAC. ${ }^{*} P<0.001$ ISO versus basal. (c) Myocardial $\beta A R / G_{s}$ coupling (percentage of high affinity) in sarcolemmal membranes prepared from hearts of WT sham $(n=3)$, WT TAC $(n=4)$, and $\mathrm{PI} 3 \mathrm{~K} \gamma_{\text {inact }}(n=3)$ mice. ${ }^{*} P<0.01 \mathrm{WT}$ TAC versus either WT sham or PI3K $\gamma_{\text {inact }}$ TAC. (d) Proposed model of the mechanism by which overexpression of PI $3 K \gamma_{\text {inact }}$ transgene prevents $\beta A R$ downregulation. Overexpression of $\mathrm{PI} 3 \mathrm{~K} \gamma_{\text {inact }}$ leads to a competitive displacement of all $\mathrm{PI} 3 \mathrm{~K}$ isoforms from the $\beta A R K 1 / \mathrm{PI} 3 \mathrm{~K}$ complex. Following agonist stimulation, the translocation of $\beta A R K 1$ recruits inactive PI3K to the activated receptor complex attenuating receptor internalization. Inhibition of receptor internalization ultimately leads to receptor dephosphorylation and resensitization either at the cell surface or through enhanced cycling of receptor without being targeted for lysosomal degradation. $G_{s}, G_{\alpha s}$ subunit of heterotrimeric $G$ protein.

mice, wherein $\beta$ ARs were significantly reduced (Figure $7 \mathrm{a})$. Since heart failure causes uncoupling of $\beta A R$ s from $G$ proteins, we tested the ability for $\beta A R s$ to activate adenylyl cyclase in pressure-overloaded WT and $\mathrm{PI} 3 \mathrm{~K} \gamma_{\text {inact }}$ hearts. Importantly, there was complete preservation of adenylyl cyclase activity in $\mathrm{PI} 3 \mathrm{~K} \gamma_{\text {inact }}$ mice compared with the WT, despite the exposure to chronic pressure overload (Figure $7 \mathrm{~b}$ ). To determine whether the preservation of cyclase activity was the result of enhanced $\beta A R-G$ protein coupling, competition binding was carried out on membrane fractions from the hearts of WT and PI $3 \mathrm{~K} \gamma_{\text {inact }}$ banded mice. The number of $\beta A R s$ in the high-affinity state was significantly greater in PI $3 \mathrm{~K} \gamma_{\text {inact }}$ hearts compared with WT hearts $(P<0.01)$ after 12 weeks of TAC and equal to the level in the WT sham (Figure 7c). These data show that $\beta A R$ density and $\beta A R-G_{\alpha s}$ subunit of heterotrimeric $G$ protein effector coupling was preserved in hearts of $\mathrm{PI} 3 \mathrm{~K} \gamma_{\text {inact }}$ mice despite being subjected to chronic pressure overload, a stimulus that normally induces significant alterations in $\beta A R$ signaling.

\section{Discussion}

In the present investigation we identify a unique role for PI3K in regulating the level and sensitivity of $\beta A R$ function in the heart and suggest an important role for $\beta$ AR dysfunction in pressure overload-induced heart failure. We show that cardiac-targeted overexpression of a catalytically inactive PI3K prevents $\beta A R$ downregulation and desensitization with chronic catecholamine administration and ameliorates the development of cardiac dysfunction under conditions of chronic in vivo pressure overload. Our data show that overexpression of $\mathrm{PI} 3 \mathrm{~K} \gamma_{\text {inact }}$ in the hearts of transgenic mice leads to a competitive displacement of all PI3K isoforms from the $\beta A R K 1 / \mathrm{PI} 3 \mathrm{~K}$ complex such that translocation of $\beta A R K 1$ recruits catalytically inactive PI3K to activated receptors, leading to the inhibition of receptor internalization (Figure $7 d$ ). Intriguingly, we also show that the deletion of PI3K $\gamma$ in the heart is insufficient to prevent $\beta A R$ dysfunction despite its positive effect on adenylyl cyclase activity. These data suggest that the generation of PtdIns-3,4,5- $\mathrm{P}_{3}$ molecules localized within the activated receptor complex plays a critical role in regulating $\beta A R$ recycling and preserving $\beta A R$ function in vivo.

$P I 3 K$ and $\beta A R$ function. $\beta A R$ downregulation and desensitization are hallmarks of heart failure and are believed to be secondary to the chronic activation of the sympathetic nervous system and increased catecholamines that occur with circulatory failure $(2,26)$. Recent data show that preservation of $\beta$ AR function through $\beta A R K 1$ inhibition improves cardiac function in experimental models of heart failure (3-5). The mechanism for this benefit, however, is not entirely clear since $\beta A R K 1$ inhibition was carried out using overexpression of the $\beta A R K 1-c t$ peptide (c-terminal region of $\beta A R K 1$ ) that also has the ability to sequester $\mathrm{G}_{\beta \gamma}$ subunits and as a result could inhibit activation of $\mathrm{G}_{\beta \gamma}$ mediated signals. In this regard, our present study highlights a novel strategy to preserve $\beta A R$ function under conditions of catecholamine excess and heart failure upon chronic pressure overload by targeting the $\beta A R K 1 / P I 3 K$ interface. While both the PI3K $\gamma_{\text {inact }}$ and $\beta A R K-c t$ transgenes prevent receptor downregulation, the underlying mechanism for preservation of $\beta A R$ function are different. The $\beta$ ARK-ct peptide sequesters 
liberated $G_{\beta \gamma}$ subunits, thereby inhibiting $\beta$ ARK1mediated phosphorylation of $\beta$ ARs (27). In contrast, overexpression of PI3K $\gamma_{\text {inact }}$ transgene does not inhibit receptor phosphorylation as we show by in vitro rhodopsin phosphorylation but, rather, prevents subsequent process involved in receptor internalization (8).

The effect on $\beta$ AR function was found to be specific to the disruption of the $\beta$ ARK1/PI3K interaction, since mice that completely lack the PI $3 \mathrm{~K} \gamma$ gene (PI3K $\gamma-\mathrm{KO})$ showed a similar downregulation of $\beta$ ARs and diminished agonist-stimulated adenylyl cyclase activity when exposed to chronic catecholamines. This is particularly interesting given the recently identified role of PI3K $\gamma$ in regulating adenylyl cyclase activity $(9,12)$. PI $3 \mathrm{~K} \gamma-\mathrm{KO}$ mice have been shown to have enhanced contractility and elevated basal and agonist-stimulated adenylyl cyclase activity (ref. 9; Figure 4c). Despite this enhanced adenylyl cyclase activity, however, chronic ISO administration leads to desensitization and downregulation of $\beta A R s$. Importantly, $\beta A R K 1$-associated PI3K activity in the hearts of PI3K $\gamma-\mathrm{KO}$ mice was similar compared with the WT, and we show that $\beta$ ARK1 interacts with the PI3K $\alpha$ isoform in the hearts of these mice (10). Based on the phenotype of these two mouse models (PI3K $\gamma_{\text {inact }}$ and $\left.\mathrm{PI} 3 \mathrm{~K} \gamma-\mathrm{KO}\right)$, we postulate that overexpression of the dominant negative PI3K transgene leads to a reduction in $\beta$ ARK1-associated PI3K activity, which plays a critical role in preventing the downregulation and desensitization of the $\beta$ ARs under conditions of chronic agonist stimulation. Furthermore, the membrane recruitment of PI3K appears to be an early event in the regulation of $\beta$ AR function and is consistent with our in vitro studies showing its role in receptor internalization within minutes of agonist stimulation (10). Thus, our data identify a new role for PI3K in maintaining the level of $\beta$ ARs in the heart. Whereas PI3K $\gamma$ may directly regulate cyclase activity (9), the recruitment of any active PI3K isoform to the receptor complex promotes the downregulation of $\beta$ ARs. Our data have important implications regarding the potential development of PI3K $\gamma$ inhibitors to augment cardiac contractility (9). Without preventing the $\beta$ ARK1mediated recruitment of active PI3K to the cell membrane, a selective inhibitor of PI3K $\gamma$ would not prevent the $\beta A R$ abnormalities or the contractility defects in heart failure.

Resensitization allows $\beta$ ARs to renew their ability to respond to ligand and has been shown to require internalization into intracellular compartments where the acidic environment allows for dephosphorylation of the receptor $(28,29)$. An interesting finding of this study is that resensitization of $\beta$ ARs in vivo may occur under conditions that prevent receptor internalization despite continuous exposure to agonist. One potential explanation for this phenomenon is the targeting of phosphatases to agonist-occupied receptors $(30,31)$, which could promote dephosphorylation of the receptor at the plasma membrane without the cycling into early endosomes. Alternatively, it is possible that $\beta$ ARs are inter- nalized but undergo rapid recycling without being targeted for lysosomal degradation, a process thought to require PI3K activity $(32,33)$. Future studies that use in vitro models of $\beta A R$ desensitization will be required to determine the exact mechanism of $\beta A R$ resensitization in this system. Finally, we cannot exclude the possibility that the PI3K $\gamma_{\text {inact }}$ transgene affects some other signaling pathway that ameliorates cardiac dysfunction, leading to a reversal in the $\beta A R$ defect.

$P I 3 K$ and downstream cellular signaling. PI $3 \mathrm{~K} \gamma_{\text {inact }}$ overexpression did not affect the immediate downstream signaling with either GPCR or growth factor stimulation and did not inhibit the development of cardiac hypertrophy to short-term pressure overload. Although basal pPKB levels are lower in the PI $3 \mathrm{~K} \gamma_{\text {inact }}$ transgenic mice compared with the WT, acute and chronic stimulation leads to $\mathrm{PKB}$ activation possibly due to availability of liberated $\mathrm{G}_{\beta \gamma}$ to activate endogenous PI3Ks and/or through transactivation of tyrosine kinase receptors such as the epidermal growth factor $(34,35)$. This supports our understanding that $\mathrm{PI} 3 \mathrm{~K} \gamma_{\text {inact }}$ overexpression specifically disrupts the $\beta A R K 1 / \mathrm{PI} 3 \mathrm{~K}$ interaction without affecting the acute activation of receptor-mediated downstream PI3K signals. Increasing evidence supports a role for PI3K in determining cardiac growth (13). Cardiac overexpression of a catalytically inactive PI $3 \mathrm{~K} \alpha$ $(\mathrm{dnPI} 3 \mathrm{~K} \alpha)$ was shown to result in reduced heart weight and cardiomyocyte size compared with WT, whereas overexpression of constitutively active PI3K $\alpha$ developed a hypertrophic phenotype suggesting a specific regulatory role for the PI3K $\alpha$ isoform in the control of myocyte growth (13). Moreover, mice deficient in phosphatase and tensin homolog deleted on chromosome 10 (PTEN) showed spontaneous cardiac hypertrophy and reduced contractility, indicating a role of phosphatidylinositol signaling in cardiac growth (9). In contrast, in our study mice overexpressing PI $3 \mathrm{~K} \gamma_{\text {inact }}$ had no effect on cardiac growth under normal or stressed conditions. The likely explanation for the difference in the mouse phenotypes relates to the different transgenes that were used in the two studies. We overexpressed the inactive PI3K $\gamma$ isoform that contained all the domains except for the ATP-binding site. In contrast, the dnPI3K $\alpha$ transgene used by Shioi et al. (13) lacked the PIK domain that is necessary for its interaction with $\beta A R K 1$ (8). Thus, overexpression of dnPI3K $\alpha$ would not displace endogenous PI3K from $\beta$ ARK1, but would act to sequester adaptor proteins involved in PI $3 \mathrm{~K} \alpha$ signaling pathways. Our data in this study show that competitive displacement of PI3K from the $\beta$ ARK1 complex is critical to preserve $\beta A R$ function and prevent $\beta A R$ downregulation in chronic disease states.

In conclusion, we demonstrate a new role for PI3K in regulating GPCR signaling in vivo. Overexpression of catalytically inactive PI3K $\gamma$ displaces active endogenous PI3K from $\beta A R K 1$ and leads to preservation of $\beta A R$ function under conditions of chronic catecholamine administration and chronic pressure overload. Targeting PI3K $\gamma$ directly would be insufficient as a therapeutic 
strategy, but, rather, one would need to disrupt recruitment of PI3K to activated $\beta A R s$ to prevent receptor desensitization and downregulation. While the increased contractile phenotype of the PI3K $\gamma$-KO mice (9) suggests a direct action of PI3K $\gamma$ on the catalytic activity of adenylyl cyclase, displacement of endogenous active PI3K from $\beta$ ARK1 is necessary to modulate receptor function. Finally, we show that normalization of $\beta A R$ function is associated with the amelioration of the heart failure phenotype induced by pressure overload and suggests that $\beta A R$ dysfunction may be involved in the pathogenesis of this disease. These findings may have important clinical implications for the treatment of heart failure, where circulating catecholamines are known to be increased leading to marked $\beta A R$ dysfunction. Inhibition of $\beta A R$-localized PI3K activity may therefore represent a novel therapeutic strategy to restore $\beta$ AR function.

\section{Acknowledgments}

This work was supported in part by the NIH (grant HL-56687 to H.A. Rockman) and the Burroughs Wellcome Fund (to H.A. Rockman). J.J. Nienaber is a research fellow supported by the Stanley J. Sarnoff Endowment for Cardiovascular Science. H.A. Rockman is a recipient of a Burroughs Wellcome Fund Clinical Scientist Award in Translational Research. We thank Weili Zou for her excellent technical assistance and Liza Barki-Harrington for her valuable critique and scientific insights.

1. Hunt, S.A., et al. 2001. ACC/AHA guidelines for the evaluation and management of chronic heart failure in the adult: executive summary. A report of the American College of Cardiology/American Heart Association Task Force on Practice Guidelines (Committee to Revise the 1995 Guidelines for the Evaluation and Management of Heart Failure). Circulation. 104:2996-3007.

2. Cohn, J.N., et al. 1984. Plasma norepinephrine as a guide to prognosis in patients with chronic congestive heart failure. N. Engl.J. Med. 311:819-823.

3. Rockman, H.A., Koch, W.J., and Lefkowitz, R.J. 2002. Seven-transmembrane-spanning receptors and heart function. Nature. 415:206-212.

4. Akhter, S.A., et al. 1999. In vivo inhibition of elevated myocardial betaadrenergic receptor kinase activity in hybrid transgenic mice restores normal beta-adrenergic signaling and function. Circulation. 100:648-653

5. Harding, V.B., Jones, L.R., Lefkowitz, R.J., Koch, W.J., and Rockman, H.A. 2001. Cardiac beta ARK1 inhibition prolongs survival and augments beta blocker therapy in a mouse model of severe heart failure. Proc. Natl. Acad. Sci. U. S. A. 98:5809-5814.

6. Foody, J.M., Farrell, M.H., and Krumholz, H.M. 2002. $\beta$-Blocker therapy in heart failure: scientific review. JAMA. 287:883-889.

7. Lefkowitz, R.J. 1998. G protein-coupled receptors. III. New roles for receptor kinases and beta-arrestins in receptor signaling and desensitization. J. Biol. Chem. 273:18677-18680.

8. Naga Prasad, S.V., et al. 2002. Phosphoinositide 3-kinase regulates beta2adrenergic receptor endocytosis by AP-2 recruitment to the receptor/beta-arrestin complex. J. Cell Biol. 158:563-575.

9. Crackower, M.A., et al. 2002. Regulation of myocardial contractility and cell size by distinct PI3K-PTEN signaling pathways. Cell. 110:737-749.

10. Naga Prasad, S.V., Barak, L.S., Rapacciuolo, A., Caron, M.G., and Rockman, H.A. 2001. Agonist-dependent recruitment of phosphoinositide 3 -kinase to the membrane by beta-adrenergic receptor kinase 1 . A role in receptor sequestration. J. Biol. Chem. 276:18953-18959.

11. Vanhaesebroeck, B., et al. 2001. Synthesis and function of 3-phosphorylated inositol lipids. Annu. Rev. Biochem. 70:535-602.
12. Jo, S.H., Leblais, V., Wang, P.H., Crow, M.T., and Xiao, R.P. 2002. Phosphatidylinositol 3-kinase functionally compartmentalizes the concurrent $\mathrm{G}(\mathrm{s})$ signaling during beta2-adrenergic stimulation. Circ. Res. 91:46-53.

13. Shioi, T., et al. 2000. The conserved phosphoinositide 3-kinase pathway determines heart size in mice. EMBO J. 19:2537-2548.

14. Naga Prasad, S.V., Esposito, G., Mao, L., Koch, W.J., and Rockman, H.A. 2000. Gbetagamma-dependent phosphoinositide 3-kinase activation in hearts with in vivo pressure overload hypertrophy. J. Biol. Chem. 275:4693-4698

15. Gaidarov, I., and Keen, J.H. 1999. Phosphoinositide-AP-2 interactions required for targeting to plasma membrane clathrin-coated pits. J. Cell Biol. 146:755-764.

16. Ma, A.D., Metjian, A., Bagrodia, S., Taylor, S., and Abrams, C.S. 1998. Cytoskeletal reorganization by $\mathrm{G}$ protein-coupled receptors is dependent on phosphoinositide 3-kinase gamma, a Rac guanosine exchange factor, and Rac. Mol. Cell. Biol. 18:4744-4751.

17. Li, Z., et al. 2000. Roles of PLC-beta2 and -beta3 and PI3Kgamma in chemoattractant-mediated signal transduction. Science. 287:1046-1049.

18. Esposito, G., et al. 2002. Genetic alterations that inhibit in vivo pressureoverload hypertrophy prevent cardiac dysfunction despite increased wall stress. Circulation. 105:85-92.

19. Iaccarino, G., Tomhave, E.D., Lefkowitz, R.J., and Koch, W.J. 1998. Reciprocal in vivo regulation of myocardial $G$ protein-coupled receptor kinase expression by beta-adrenergic receptor stimulation and blockade. Circulation. 98:1783-1789.

20. Choi, D.J., and Rockman, H.A. 1999. Beta-adrenergic receptor desensitization in cardiac hypertrophy and heart failure. Cell Biochem. Biophys. 31:321-329.

21. Subramaniam, A., et al. 1991. Tissue-specific regulation of the alphamyosin heavy chain gene promoter in transgenic mice. J. Biol. Chem. 266:24613-24620.

22. Pitcher, J.A., Freedman, N.J., and Lefkowitz, R.J. 1998. G protein-coupled receptor kinases. Annu. Rev. Biochem. 67:653-692.

23. Choi, D.J., Koch, W.J., Hunter, J.J., and Rockman, H.A. 1997. Mechanism of beta-adrenergic receptor desensitization in cardiac hypertrophy is increased beta-adrenergic receptor kinase. J. Biol. Chem. 272:17223-17229.

24. Cho, M.C., et al. 1999. Defective beta-adrenergic receptor signaling precedes the development of dilated cardiomyopathy in transgenic mice with calsequestrin overexpression. J. Biol. Chem. 274:22251-22256.

25. Rockman, H.A., et al. 1998. Expression of a beta-adrenergic receptor kinase 1 inhibitor prevents the development of myocardial failure in gene-targeted mice. Proc. Natl. Acad. Sci. U. S. A. 95:7000-7005.

26. Bristow, M.R., et al. 1982. Decreased catecholamine sensitivity and betaadrenergic-receptor density in failing human hearts. N. Engl. J. Med. 307:205-211.

27. Koch, W.J., et al. 1995. Cardiac function in mice overexpressing the betaadrenergic receptor kinase or a beta ARK inhibitor. Science. 268:1350-1353.

28. Krueger, K.M., Daaka, Y., Pitcher, J.A., and Lefkowitz, R.J. 1997. The role of sequestration in $\mathrm{G}$ protein-coupled receptor resensitization. Regulation of beta2-adrenergic receptor dephosphorylation by vesicular acidification. J. Biol. Chem. 272:5-8.

29. Perry, S.J., and Lefkowitz, R.J. 2002. Arresting developments in heptahelical receptor signaling and regulation. Trends Cell Biol. 12:130-138.

30. Lin, F., Wang, H., and Malbon, C.C. 2000. Gravin-mediated formation of signaling complexes in beta 2 -adrenergic receptor desensitization and resensitization. J. Biol. Chem. 275:19025-19034.

31. Shih, M., Lin, F., Scott, J.D., Wang, H.Y., and Malbon, C.C. 1999. Dynamic complexes of beta2-adrenergic receptors with protein kinases and phosphatases and the role of gravin. J. Biol. Chem. 274:1588-1595.

32. Clague, M.J., and Urbe, S. 2001. The interface of receptor trafficking and signalling. J. Cell Sci. 114:3075-3081.

33. Zerial, M., and McBride, H. 2001. Rab proteins as membrane organizers. Nat. Rev. Mol. Cell Biol. 2:107-117.

34. Saward, L., and Zahradka, P. 1997. Angiotensin II activates phosphatidylinositol 3-kinase in vascular smooth muscle cells. Circ. Res. 81:249-257.

35. Kim, J., Eckhart, A.D., Eguchi, S., and Koch, W.J. 2002. Beta-adrenergic receptor-mediated DNA synthesis in cardiac fibroblasts is dependent on transactivation of the epidermal growth factor receptor and subsequent activation of extracellular signal-regulated kinases. J. Biol. Chem. 277:32116-32123. 